\title{
A Review of Thermal Conductivity Models for Nanofluids
}

\author{
HIKMET Ş. AYBAR, ${ }^{1}$ MOHSEN SHARIFPUR, ${ }^{2}$ M. REZA AZIZIAN, ${ }^{3}$ MEHDI \\ MEHRABI, ${ }^{2}$ and JOSUA P. MEYER ${ }^{2}$ \\ ${ }^{1}$ Department of Mechanical Engineering, Eastern Mediterranean University, G. Magosa, \\ KKTC, Mersin 10, Turkey \\ ${ }^{2}$ Department of Mechanical and Aeronautical Engineering, University of Pretoria, Pretoria, \\ 0002, South Africa \\ ${ }^{3}$ Priority Research Centre for Energy, University of Newcastle, Australia
}

Nanofluids, as new heat transfer fluids, are in the centre of attention of researchers while their measured thermal conductivities are more than conventional heat transfer fluids. Unfortunately, conventional theoretical and empirical models cannot explain the enhancement of the thermal conductivity of nanofluids. Therefore, it is important to understand the fundamental mechanisms as well as the important parameters which influence the heat transfer in nanofluids. Nanofluids thermal conductivity enhancement consists of four major mechanisms: Brownian motion of the nanoparticle, nanolayer, clustering, and the nature of heat transport in the nanoparticles. Important factors which affect the thermal conductivity modelling of nanofluids are particle volume fraction, temperature, particles size, $\mathrm{pH}$, and the size and property of nanolayer. In this paper, each mechanism is explained and proposed models are critically reviewed. It is concluded that there is a lack of reliable hybrid model which includes all mechanisms and influenced parameters for thermal conductivity of nanofluids. Furthermore, more work needs to be conducted on the nature of heat transfer in nanofluids. A reliable database and experimental data are also needed on the properties of nanoparticles.

Address correspondence to: Hikmet Ş. Aybar, Department of Mechanical Engineering, Eastern Mediterranean University, G. Magosa, KKTC, Mersin 10, Turkey

E-mail: hikmet.aybar@emu.edu.tr

Tel: +903926301451

Fax: +903923653715 


\section{INTRODUCTION}

As technology progresses, high-energy microelectronic devices (e.g. electronic chips, laser applications) tend to be minimized in the size. They generate more thermal energy and this thermal energy needs to be removed. Therefore, enhancement of the heat flux is a critical research area. One of the major limitations is the thermal conductivity of the conventional heat transfer fluids. The thermal conductivity of the fluids is about two orders lower in magnitude in comparison with metals. Consequences, the use of solid particles as an additive suspended in a base fluid is a promising technique in order to increase the heat transfer characteristics of heat transfer fluids [1]. However, corrosion can cause the limitation for base fluid choices which makes the metal oxides as alternative for conventional heat transfer fluids.

Scattering solid particles into liquids is not a new idea, since it can be traced back to Maxwell's theoretical work of 1873 [2]. Maxwell considered suspended particles which had dimensions of micrometre and millimetre level. However, the particles of these dimensions cause problems of rapid settling, abrasion and clogging. Furthermore, Xuan and Li [3] found that fluids with these particle dimensions have limited applications in heat transfer enhancement. Nanofluids, however, have the potential to reduce suspension problems.

Nanofluids [4] consist of solid nanoparticles smaller than $100 \mathrm{~nm}$ suspended in a liquid. This type of working fluid shows an extremely high heat transfer performance. The increase in the thermal conductivity of nanofluids is not only because of the conduction, but also because of other mechanisms causing a significant increase in thermal conductivity. Up to the present, the fundamental mechanism of the enhanced thermal conductivity of nanofluids remains a key challenge in nanofluids research. Although some valuable review papers [5-10] have been published on different aspects of heat transfer in nanofluids, there is still a need to evaluate different models and identify gaps for future research. In this review paper, each mechanism affecting thermal conductivity of nanofluids is reviewed separately and then the recent models are discussed.

\section{HEAT TRANSFER MECHANISMS IN NANOFLUIDS}

A nanofluid is a new type of heat transfer fluid used in engineering applications, and it is simply a base fluid with nanoparticles suspended. They show a significant enhancement in thermal conductivity. This enhancement is related to better thermal conductivity of the solid particles than that of the base fluid as well as the high specific surface area of the nanoparticles. The specific surface area of the nanoparticles could be 1000 times larger than that of microparticles, and because of the heat transfer occurs on the surface of the particles, the high specific surface area of the nanoparticles enhances the heat transfer conduction capability of nanofluids [11]. 
Heat transfer conduction means vibration of atoms that are coupled together. The energy of the vibrating system is quantised, and phonon is the emission or absorption of quantised thermal energy by an atom. Therefore, a phonon is essentially a quantised mode of vibration which plays a main role in the thermal conductivity of a material. A greater phonon density exists in the hot region than in the cooler one; therefore, heat conduction is essentially due to the diffusion of phonons from the hot region to the cold region.

An idea for the effective thermal conductivity of mixtures is to assume that the diffusive heat transfer occurs in both fluid and solid phases. However, models based on this assumption can be proper for large particles suspended in a base fluid [12]. They cannot predict the anomalous heat transfer characteristics of nanofluids. The important disadvantage of the macroscopic approach based on the diffusive heat transport is that the particle size does not affect the thermal conductivity. The experimental data for the thermal conductivity of different types of nanofluids show that the effective thermal conductivity is greater for smaller particles in the case of the same volume fraction. This shows that there are other parameters affecting the thermal characteristics of nanofluids.

\section{MODELS FOR THERMAL CONDUCTIVITY}

The different factors which potentially influence the heat transfer enhancement of nanofluids are Brownian motion of nanoparticles, clustering of nanoparticles, nanolayering of the liquid at the liquid/nanoparticle interface, ballistic transport and nonlocal effect, thermophoretic effect and near-field radiation[13, 14]. Up to present most of the studies have been done on the Brownian motion of the nanoparticles, molecular-level layering of the liquid at the liquid/particle interface (nanolayer), nanoparticle clustering, and a combination of these factors together with other conditional parameters as temperature, nanoparticles size and volume fraction.

\section{Brownian motion}

In a conventional approach, the effect of the particle Brownian motion is neglected due to the large particle size. As the particle size approaches the nanometre scale, the particle Brownian motion and its effect on the surrounding liquids involve the heat transfer. The contribution of Brownian motion of nanoparticles in order to enhance the thermal conduction could be in two different ways: first due to the movement of the nanoparticles which can transfer the heat and the second way is the microconvection of the fluid around individual nanoparticles. The first one has been shown theoretically to be negligible [13]. The second one has also been shown a minor effect on the thermal conductivity by theoretical analysis [15].

Nanoparticles in nanofluids provide random motions with a corresponding enhancement in thermal conductivity. Therefore, the effective thermal conductivity of nanofluids depends 
on the nanostructures of the suspensions as well as the dynamics of the nanoparticles in the base liquids. Consequently, one of the considerations in order to develop a model must be the movement of the nanoparticles as a result of the interactions between nanoparticles and the liquid molecules [11].

Keblinski et al. [13] performed molecular dynamics (MD) simulations to calculate the thermal conductivity of a simple model of the liquid and solid by using the Green-Kubo relationships. Their results demonstrated that the effect of collision between nanoparticles due to Brownian motion is not significant since the ratio of thermal diffusion to Brownian motion is much higher. Even for a particle size equal to atomic size the ratio is order of 25 . Furthermore, they bring in attention that the Brownian motion may affect in forming particle clusters which can improve the thermal conductivity of nanofluids.

Xuan et al. [16] offered a model that takes into account the effect of Brownian motion and the aggregation structure of nanoparticle clusters. Their simulation is unique from the point of view of including the fluid temperature and the structure of nanoparticle clusters in the thermal conductivity [11]. The resulting model expressed as

$$
\frac{k_{e f f}}{k_{b f}}=\frac{k_{p}+2 k_{b f}-2 \phi\left(k_{b f}-k_{p}\right)}{k_{p}+2 k_{b f}+\phi\left(k_{b f}-k_{p}\right)}+\frac{\rho_{p} \phi c_{p}}{2 k_{b f}} \sqrt{\frac{K_{B} T}{3 \pi \mu r_{c}}}
$$

In spite of the fact that their model is among pioneer models to include the Brownian motion effect, it cannot predict the linear increase of conductivity with temperature, as obtained by Das et al. [17].

Yu et al. [18] provided a model for the thermal conductivity of a nanofluid based on onedimensional drift velocity model. They showed that the drift velocity in the presence of a temperature gradient and the collision of particles could effect as a small fraction of the enhancement. Their work is significant in proposing a new mechanism of nanoconvection without fitting parameters.

Das et al. [17] explained that the main mechanism for thermal conductivity enhancement in nanofluids can be stochastic motion of the nanoparticles. They indicated that the Brownian motion was not important in the conducting behaviour at low temperatures. They also showed the possibility of a threshold temperature corresponding to each particle size in which the effective thermal conductivity of nanofluids commences to enhance through stochastic motion of the particles. They finally indicated that the stochastic motion of the particles will be greater for smaller particles.

Jang and Choi [19] conducted a study in order to account the Brownian motion behaviour of nanoparticles. Figure 1 shows their model which consists of four modes of energy transport in nanofluids. The first factor is collisions of the base fluid molecules which points 
on the heat conductivity in microscale. The net energy flux of the collision across a plane at $z$ is given by

$J=-k_{b f} \frac{d T}{d z}\left(1-\phi_{e f f}\right)$

The second mode is thermal diffusion in nanoparticle fluids which is given by

$J=-k_{p} \frac{d T}{d z}\left(1-\phi_{e f f}\right)$

The third one is the collisions between nanoparticles as a result of Brownian motion. This collision is a slow process because the heating time scales is much greater than the Brownian motion time scales [13]. This implies that the movement of nanoparticles due to Brownian motion is a very slow phenomenon in order to transport significant heat through a nanofluid. The fourth mode is thermal interactions of dynamic or dancing nanoparticles with base fluid molecules. Jang and Choi [19] postulated that the Brownian motion of nanoparticles in nanofluids produces convection-like effects on a nanoscale level, and it can be defined by $J=-h \delta_{T} \frac{d T}{d z}\left(1-\phi_{e f f}\right)$

where $h$ is the heat transfer coefficient and it is for the flow passed the nanoparticles as

$h \approx \frac{k_{b f}}{d_{p}} \operatorname{Re}_{d_{p}}^{2} \operatorname{Pr}^{2}$

Finally, the resultant model can be expressed as

$k_{e f f}=k_{b f}\left(1-\phi_{e f f}\right)+B k_{p} \phi_{e f f}+C_{p c o} \frac{d_{b f}}{d_{p}} k_{b f} \operatorname{Re}_{d_{p}}^{2} \phi_{e f f}$

where $B$ is a constant for the Kapitza resistance per unit area, $C_{p c o}$ is a proportional constant, and the Reynolds number is defined by

$\operatorname{Re}_{d_{p}}=\frac{D_{0} d_{p}}{l_{b f} \mu_{b f}}$

where $D_{0}, l_{b f}$ and $\mu_{b f}$ are the diffusion coefficient, the liquid mean free path and dynamic viscosity of base fluid, respectively.

Their model is focused on the heat transfer between particles and carrier fluids which is not directly related to the heat transfer phenomena in the fixed reference frame. The advantage of the model is the effects of particle size, temperature and particle volume 
fraction. However, the Brownian effect was counted since the high temperature-dependent properties may be caused by the Brownian motion [12].

Bhattacharya et al. [20] developed a model for effective thermal conductivity of nanofluids based on Brownian dynamic simulations and the equilibrium Green-Kubo method. Their model is a linear combination of particle conductivity and liquid conductivity as

$$
k_{e f f}=\phi k_{p}+(1-\phi) k_{b f}
$$

where $k_{p}$ is substituted by the overall thermal conductivity as a result of applying the GreenKubo relation as

$$
k_{p}=\frac{1}{K_{B} T^{2} V} \sum_{j=0}^{i}<Q(0) Q(j \Delta t)>\Delta t
$$

Where $T$ is the temperature, $V$ is the volume of the domain, $i$ is the number of time steps used in the simulation, $\Delta t$ is the time step, and $\langle Q(0) Q(j \Delta t)\rangle$ is the time-autocorrelation function of $Q(t)$. By comparing the results of their simulations with the experimental data of $\mathrm{Cu}$-in-EG and alumina-in-EG, they indicated that their model can predict the effective thermal conductivity of nanofluids well. However, in their model there are some parameters that should be set such as the time step and the potential function parameters.

Kumar et al. [21], proposed a hybrid model to account for the large enhancement of the thermal conductivity of nanofluids based on the stationary particle model as well as the moving particle model. In the stationary particle model, they developed the model based on Fourier's law of diffusion; therefore, they assumed that there are two parallel paths of heat flow in the suspension, one for the nanoparticles and the other for liquid particles. In the moving particle model, they applied the Stokes-Einstein formula as well as the kinetic theory to account for the temperature effect. Finally, the effective thermal conductivity of nanoparticles is modelled by drawing a parallel to the kinetic theory of gases as

$$
\frac{k_{e f f}}{k_{b f}}=1+C_{c o} \bar{u}_{p} \frac{\phi r_{b f}}{k_{b f}(1-\phi) r_{p}}
$$

where $\bar{u}_{p}=\sqrt{\frac{2 K_{B} T}{\pi \mu d_{p}^{2}}}, C_{c o}$ is a constant, $K_{B}$ is the Boltzmann constant, $\mu$ is the dynamic viscosity, $d_{p}$ is the diameter of a particle, and $r_{p}$ is the radius of a particle. This model accounts for the dependence of thermal conductivity on particle size, volume fraction, and temperature. Predictions from the combined model agree with experimental data for nanofluids with small particle concentration. This model is one of the most popular theoretical models in nanofluids literature [22-24].

Koo and Kleinstreuer $[25,26]$ indicated that the Brownian motion produces micro-mixing therefore; it is dominant in enhancing the thermal conductivity of nanofluids. They offered a 
new model for thermal conductivity of nanofluids by adding the effect of Brownian motion to the conventional conductivity model and taking into account factors such as temperature, particle size, volume concentration, and the properties. They combined the thermal conductivity of a static dilute suspension and conductivity due to Brownian motion as follow

$k_{\text {eff }}=k_{\text {static }}+k_{\text {Brownian }}$

Wasp's model [27] was used for the static part of the model. A dynamic model of thermal conductivity due to Brownian motion of a large portion of surrounding liquid traveling with randomly moving nanoparticles was used for the second part. Finally, the model offered as

$$
k_{e f f}=\left[\frac{k_{p}+2 k_{b f}-2 \phi\left(k_{b f}-k_{p}\right)}{k_{p}+2 k_{b f}+\phi\left(k_{b f}-k_{p}\right)}\right] k_{b f}+\left[5 \times 10^{4} \beta \phi_{p} \rho_{b f} c_{b f} \sqrt{\frac{K_{B} T}{\rho_{p} d_{p}}} f\left(T, \phi_{p}, \text { etc. }\right)\right]
$$

Where $\beta$ represents the hydrodynamic interaction between particles and affected fluid and $f$ considers the augmented temperature dependence due to particle interactions. It is difficult to obtain $\beta$ as well as the function $f$ theoretically and they should be determined from experimental data for different nanofluids. For $\mathrm{Al}_{2} \mathrm{O}_{3}$-water nanofluids $\left(\phi_{p}>1 \%\right)$, $\beta=0.0017\left(100 \phi_{p}\right)^{-0.0841}, f(T, \phi)=\left(-6.04 \phi_{p}+0.4705\right) T+\left(1722.3 \phi_{p}-134.63\right)$ and it is valid for $1 \%<\phi_{p}<4 \%$ and $300 K<T<325 K$.

Prasher et al. [28] compared the effect of translational Brownian motion and convection induced by Brownian motion. They investigated into the existence of an interparticle mechanism. By making an order-of-magnitude analysis, they concluded that the local convection due to the Brownian motion of the nanoparticles is the only mechanism that could explain the anomalous enhancement of thermal conductivity of nanofluids. They also founded that the thermal conductivity for large particle sizes should be explained based on the conventional effective medium theory such as the Maxwell-Garnett model. Therefore, they modified the Maxwell-Garnett model by including the Brownian-motion-induced convection from multiple nanoparticles. Their semi-empirical model was written as

$$
k_{e f f}=\left(1+A_{e c o} \operatorname{Re}^{M_{e c o}} \operatorname{Pr}^{0.333} \phi\right)\left[\frac{k_{p}+2 k_{b f}+2\left(k_{p}-k_{b f}\right) \phi}{k_{p}+2 k_{b f}-\left(k_{p}-k_{b f}\right) \phi}\right] k_{b f}
$$

where the Reynolds number is defined as $\mathrm{Re}=\frac{1}{v} \sqrt{\frac{18 K_{B} T}{\pi \rho_{p} d_{p}}}$. Their suggested model has two empirical constants ( $A_{\text {eco }}$ and $M_{\text {eco }}$ ) which have to be determined by experiments. They indicated that Brownian motion model would be semi-empirical in nature due to the complexities involved with the interaction of multiple nanoparticles. They also suggested that a numerical simulation is needed to understand the exact origin of the empirical constants. However, Das et al. [29] replied that the applicability of the proposed model at asymptotic 
limits according to Hamilton Crosser model. They also indicated that the moving particle assumption is valid when there is a relative velocity between particles and base fluid.

Chon et al. [30] have developed empirical correlations for the effective thermal conductivity of nanofluids. Based on the Buckingham-Pi theorem with a linear regression for the experimental results, the following empirical correlation proposed for the effective thermal conductivity

$\frac{k_{e f f}}{k_{b f}}=1+64.7 \phi^{0.7460}\left(\frac{d_{b f}}{d_{p}}\right)^{0.3690}\left(\frac{k_{p}}{k_{b f}}\right)^{0.7476} \operatorname{Re}^{1.2321} \operatorname{Pr}^{0.9955}$

where $d_{b f}$ denotes the molecular diameter of base fluid. The Prandtl number and the Reynolds number are respectively defined as

$$
\begin{aligned}
\operatorname{Pr} & =\frac{\mu}{\rho_{b f} \alpha} \\
\operatorname{Re} & =\frac{\rho_{b f} u_{p} d_{p}}{\mu}=\frac{\rho_{b f} K_{B} T}{3 \pi \mu^{2} l_{b f}}
\end{aligned}
$$

The temperature dependence of the base fluid viscosity $\mu$ was expressed as $\mu=A_{c o} \times 10^{\left(\frac{B_{c o}}{T-C_{c o}}\right)}$ , where $A_{c o}, B_{c o}$ and $C_{c o}$ are constants and equal to $2.414 \times 10^{-5}, 247.8$, and 140 , for water. $u_{p}$ is the Brownian velocity of nanoparticles based on the Einstein diffusion theory

$$
u_{p}=\frac{K_{B} T}{3 \pi \mu d_{p} l_{b f}}=\frac{K_{B}}{3 \pi d_{p} l_{b f}} \cdot \frac{T}{A_{c o} \times 10^{\left(\frac{B_{c o}}{T-C_{c o}}\right)}}
$$

Ren et al. [31] offered a model which is based on kinetic-theory-based microconvection, liquid layering as well as conduction through both particles and liquid. The model includes temperature, nanoparticle concentration and particle size. They assumed a constant nanolayer thickness of $2 \mathrm{~nm}$ and taking volume-averaged over the base fluid and the particles in order to find thermal conductivity of the nanolayer.

Patel et al. [32] proposed a model for thermal conductivities of nanofluids by taking into account the specific surface area of nanoparticles and nanoconvection induced by Brownian nanoparticles. In their model, they considered kinetic theory-based micro-convection as well as liquid layering in addition to particle concentration.

Bhattacharya et al. [33] developed a semi-empirical Brownian model which shows the localised convection caused by Brownian motion is the main reason for enhancement in the effective thermal conductivity of nanofluids. Their model is a combination of the Maxwell conduction model and the convection caused by the Brownian movement of the nanoparticles. The convective-conductive model which they offered accounts for the effects of particle size, base fluid properties, thermal interfacial resistance between the particles and liquid, and temperature. The model called multisphere Brownian model (MSBM) which is a modified version of Prasher et al. model [28] 
$k_{\text {eff }}=\left(1+A_{\text {eco }} \operatorname{Re}^{M_{\text {eco }}} \operatorname{Pr}^{0.333} \phi\right)\left[\frac{\left[k_{p}(1+2 B i)+2 k_{m}\right]+2 \phi\left[k_{p}(1-B i)-k_{m}\right]}{\left[k_{p}(1+2 B i)+2 k_{m}\right]-\phi\left[k_{p}(1-B i)-k_{m}\right]}\right] k_{b f}$

where $k_{m}$ is the matrix conductivity and $B i=\frac{2 R_{b} k_{m}}{d_{p}}$ is Biot number and $R_{b}$ is thermal boundary resistance. They also showed that contrary to the Keblinski et al. [13] model, the energy transport due to Brownian diffusion is smaller than the energy transport of conduction in liquid. However, they did not consider the energy transport due to convection caused by the Brownian movement of the particles. They simply analysed that the Brownian motion time scale is greater than the convection time scale. This means that the effects of convection are almost propagated instantaneously relative to the Brownian diffusion of the particles. They also indicated that bigger particles show greater convection effects in the base fluids, regardless of the thermal conductivity of the nanoparticles. To validate the model, they compared their results with the experimental data of alumina-in-EG, Cu-in-EG, CuO-in-EG, alumina-in-oil and $\mathrm{Cu}$-in-oil. However, in their model, there are two constants which should be defined according to each experiment. Furthermore, they provided some research directions in order to remove the imperial constants.

Xu et al. [34] were the first group to develop a fractal convection model which takes into account the fractal size distribution of nanoparticle convection caused by Brownian motion. Their model takes into account the particle concentration, average size, fractal dimension and temperature. Engagingly, their model shows that the contribution of Brownian motioninduced convection reaches a maximum value at a critical concentration of $12.6 \mathrm{vol} \%$ which is in good agreement with experimental data for oxide nanofluids [11]. The model is as

$\frac{k_{e f f}}{k_{b f}}=\frac{k_{p}+2 k_{b f}-2 \phi\left(k_{b f}-k_{p}\right)}{k_{p}+2 k_{b f}+\phi\left(k_{b f}-k_{p}\right)}+H_{c o} \frac{N u d_{b f}}{\operatorname{Pr}} \frac{\left(2-D_{f}\right) D_{f}}{\left(1-D_{f}\right)^{2}} \frac{\left[\left(\frac{d_{\text {max }}}{d_{\text {min }}}\right)^{1-D_{f}}-1\right]^{2}}{\left[\left(\frac{d_{\text {max }}}{d_{\text {min }}}\right)^{2-D_{f}}-1\right]} \frac{1}{\bar{d}_{p}}$

Where $N u$ is the Nusselt number, $D_{f}$ is the fractal dimension and can be found from $D_{f}=d-\left[\ln \phi / \ln \left(d_{\min } / d_{\max }\right)\right] \cdot d=2$ in two dimensions and $d_{\min }$ and $d_{\max }$ are the minimum and maximum diameters of nanoparticles, respectively.

Evans et al. [15] developed a model for Brownian motion considering homogenous (no drift velocity) and all volume of the fluid diffuses together with the nanoparticles. They showed that the ratio of the thermal conductivity contribution due to Brownian motion with respect to the thermal conductivity of the base fluid is proportional to the ratio of the nanoparticle and base fluid thermal diffusivity. They assumed particles are well dispersed in the base fluid and then they used the molecular dynamics (MD) simulations of heat flow. Based on their kinetic theory analysis and results of MD simulation, they concluded that the 
enhancements of the thermal conductivity of nanofluids are not affected by hydrodynamic effects due to the Brownian motion. Moreover, the effective medium theory, such as the Maxwell-Garnett model, can be used for predicting the effective thermal conductivity of nanofluids with well-dispersed nanoparticles. Consequently, they offered their model as

$$
\frac{k_{e f f}}{k_{b f}}=1+3 \phi \frac{\gamma-1}{\gamma+2}
$$

where $\gamma$ is the ratio of the particle radius to the equivalent matrix thickness.

Vladkov and Barrat [35] simulated the thermal properties of nanofluids by using the molecular dynamics simulations. Based on their simulation results, they conclude that the Brownian motion of the particle does not affect the cooling process. Furthermore, the Maxwell-Garnett model can predict the effective thermal conductivity of nanofluids. They also concluded that the essential parameter which influences the effective thermal conductivity is the ratio of the Kapitza length to the particle radius. Therefore, heat transfer enhancements observed in nanofluids comes from aggregation effects, such as particle clustering and percolation or cooperative heat transfer modes. Their final expression for the effective thermal conductivity is as

$\frac{k_{e f f}}{k_{b f}}=\frac{\left(\frac{k_{p}}{k_{b f}}(1+2 \Omega)+2\right)+2 \phi\left(\frac{k_{p}}{k_{b f}}(1-\Omega)-1\right)}{\left(\frac{k_{p}}{k_{b f}}(1+2 \Omega)+2\right)-\phi\left(\frac{k_{p}}{k_{b f}}(1-\Omega)-1\right)}$

where $\Omega=\varsigma k_{b f} / r_{p}$ is the ratio between the Kapitza length (equivalent thermal thickness of the interface) and the particle radius.

$\mathrm{Li}$ and Peterson [36] analyzed the mixing effect of the base fluid directly adjacent to the nanoparticles due to the Brownian motion of nanoparticles by using CFX 5.5.1 software in order to simulate the corresponding temperature, pressure, and velocity fields. They investigated the effects of single, adjacent, and multiple nanoparticles. Their results imply that Brownian motion induced microconvection and the mixing significantly enhances the macroscopic heat transfer in the nanofluids. Moreover, Brownian motion is one of the important factors for anomalous enhancement of the effective thermal conductivity of nanofluids.

Sarkar and Selvam [37] developed the nanofluids system that consist of a base fluid of argon and copper particles with various nanoparticles concentrations. They used an equilibrium molecular dynamics simulation to model this nanofluid system. Therefore, by applying the Green-Kubo relation calculated the thermal conductivity of the base fluid and nanofluids. They found that the effective thermal conductivity of copper-argon nanofluids 
was much greater than predicted by the Hamilton-Crosser model at both of low volume concentration (up to $0.4 \%$ ) and high volume concentration (up to $8 \%$ ). They also found that the liquid atoms motion in nanofluids increases considerably in comparison with the pure base fluid (1.41 times for $1 \%$ nanofluid). The nanoparticle motion was also 28 times slower than that of the liquid phase for $1 \%$ nanofluids. This implies that the Brownian motion of the nanoparticles is too slow to transport the heat. On the other hand, localized fluid movement around nanoparticles is induced by much faster liquid atoms. They concluded that these phenomena are the main mechanism for enhanced thermal conductivity of nanofluids. However, their simulation considered only single nanoparticles and excluded the effects of aggregation.

Yu-Hua et al. [38] analysed the mechanism of the thermal conductivity of a nanofluid including the Brownian motion effect, particle agglomeration and viscosity as well as the influence of the temperature. Their model combined the Maxwell model and the Brownian motion effect based on Xuan et al. [16] work. They considered while the particles are on a nano-scale, the surface area of the particles is larger and this could influence the performance of the particles. Therefore, they calculated the thermal conductivity of the nanoparticles as

$$
\frac{k_{e f f}}{k_{b f}}=\frac{k_{p_{e f f}}+2 k_{b f}-2 \phi_{e f f}\left(k_{b f}-k_{p_{e f f}}\right)}{k_{p_{e f f}}+2 k_{b f}+\phi_{e f f}\left(k_{b f}-k_{p_{e f f}}\right)}+\frac{\rho_{p} \phi_{e f f} c_{p}}{2 k_{b f}} \sqrt{\frac{K_{B} T}{3 \pi \mu r_{c}}}
$$

where $\phi_{\text {eff }}=\left(1+\frac{l_{t}}{r_{p}}\right)^{3} \phi$ and $l_{t}$ is the thickness of the liquid layer which can be expressed as $l_{t}=\frac{1}{\sqrt{3}}\left(\frac{4 m_{m w}}{\rho_{b f} N_{A}}\right)^{\frac{1}{3}}$

where $m_{m w}$ is the molecular weight of the liquid on the solid interface and $N_{A}$ is Avogadro's constant. They also showed that the changes of viscosity and particle agglomeration with temperature are important issues. By increasing the temperature, the reduction of the particle surface energy would decrease the agglomeration of nanoparticles, and the reduction of viscosity would improve the Brownian motion. To validate their model, they compared the model with the experimental results of $\mathrm{Cu}$-water and which were in good agreement. The results indicated that the maximum error decreased from $7 \%$ to $3 \%$ when the temperature effects of agglomeration nanoparticles were taken into account.

Shukla and Dhir [39] developed a microscopic model for predicting the thermal conductivity of nanofluids based on the Brownian motion of nanoparticles in the liquid. They divided the net heat flux due to Brownian motion into a kinetic and an interaction parts. Their model is based on ensemble averaging technique assuming the existence of small departures from equilibrium and the presence of pairwise-additive interaction potential between various nanoparticles as 


$$
\begin{aligned}
& k_{\text {eff }}=\left\{\frac{k_{p}+2 k_{b f}+2 \phi\left(k_{p}-k_{b f}\right)}{k_{p}+2 k_{b f}-\phi\left(k_{p}-k_{b f}\right)}\right\} k_{b f}+\phi \frac{\rho_{p} c_{p} K_{B} T}{\gamma}+ \\
& \left\{\frac{n K_{B}^{2} T}{\gamma}\right\}\left\{\frac{(1-\phi) Z}{8\left(1+\left(\rho_{i} / n Z\right)\right)}\right\}\left\{\frac{3.29\left(r_{p} \kappa_{D}\right)^{2}+3.61\left(r_{p} \kappa_{D}\right)+1.89}{a \kappa_{D}\left(1+r_{p} \kappa_{D}\right)^{2}}\right\}+ \\
& \left\{\frac{\rho_{p} c_{p} K_{B} T}{\gamma}\right\}\left\{\frac{(1-\phi) Z}{16\left(1+\left(\rho_{i} / n Z\right)\right)}\right\}\left\{\frac{9.87\left(r_{p} \kappa_{D}\right)^{2}+21.64\left(r_{p} \kappa_{D}\right)+17.05}{r_{p} \kappa_{D}\left(1+r_{p} \kappa_{D}\right)^{2}}\right\}+ \\
& \left\{\frac{\rho_{p} c_{p} K_{B} T}{\gamma}\right\}\left\{\frac{(1-\phi)^{2} Z^{2}}{48\left(1+\left(\rho_{i} / n Z\right)\right)^{2}}\right\}\left\{\frac{1.92\left(r_{p} \kappa_{D}\right)^{4}+1.80\left(r_{p} \kappa_{D}\right)^{3}+1.05\left(r_{p} \kappa_{D}\right)^{2}+0.29\left(r_{p} \kappa_{D}\right)}{\left(1+r_{p} \kappa_{D}\right)^{4}}\right\}
\end{aligned}
$$

where $\rho_{i}$ is the number density of ionic charge in the bulk liquid, $n Z$ accounts for the contribution of charged nanoparticles through the number of counterions and $r_{p} \kappa_{D}$ stands for the non-dimensional inverse Debye length. $\kappa_{D}$ is defined as

$$
\kappa_{D}=\left(\frac{4 \pi l_{B}\left(\rho_{i}+n Z\right)}{1-\phi}\right)^{\frac{1}{2}}
$$

where the Bjerrum length $l_{B}$ is $l_{B}=e^{2} /\left(4 \pi \varepsilon K_{B} T\right)$.

In the model, the kinetic contribution to the effective thermal conductivity was neglected. The specific form of the repulsive DLVO potential which accounts for the electrostatic repulsion between charged spherical nanoparticles was also selected to design the interparticle interaction between various nanoparticles. They analyzed the interparticle potential effect on thermal conductivity through calculations involving DLVO interaction between the electric double layers on spherical nanoparticles. These calculations show the importance of long-range repulsive potentials for the enhancement of thermal conductivity of nanofluids.

Yang [40] developed a thermal conductivity model based on the kinetic theory of particles in the fluids under relaxation time approximations. The model takes into account convective heat transfer due to the Brownian motion of nanoparticles. It is also expressed as a combination of diffusive heat conduction and the particle Brownian motion as

$$
k_{\text {eff }}=k_{\text {diff }}+k_{\text {Brownian }}
$$

where $k_{\text {diff }}$ is 
$k_{d i f f}=\left[1+3 \phi \frac{\frac{r_{p}}{R_{b} k_{b f}}-1}{\frac{r_{p}}{R_{b} k_{b f}}+2}\right] k_{b f}$

where $\phi=(4 / 3) \pi r_{p}^{3}$ is the volume of the particle, $r_{p}$ is the particle radius and $R_{b}$ is the thermal resistance per unit area of the particle/ fluid interface. The second term of Eq. (26) is corresponded to the convection due to the Brownian motion of the nanoparticles. It is analytically derived from integration of the fluid velocity over the hydrodynamic boundary layer around the Brownian particle and expressed as

$k_{\text {Brownian }}=157.5 \phi c_{f} u_{p}^{2} \tau$

where $c_{f}$ is the heat capacity per unit volume of the fluid, $\tau$ is the particle relaxation time, and $u_{p}$ is the Brownian velocity of the particle which two former ones are expressed as

$\tau=\frac{m_{p}}{6 \pi \mu_{b f} r_{p}}$
$u_{p}=\sqrt{\frac{3 K_{B} T}{m_{p}}}$

where $K_{B}$ is the Boltzmann constant and $m_{p}$ is the mass of the particle.

Furthermore, he founded that the relaxation time of particle Brownian motion could be significantly affected by the long-time tail in Brownian motion.

Nie et al. [41] represented a new valuable mathematical model based on the Green-Kubo linear theory. They used the exact expression for the heat flux vector of the base fluid with the nanoparticles to estimate the contribution of nanoparticle Brownian motion to the thermal conductivity of the nanofluid. They derived an equation for the contribution of the enhancement of thermal conductivity due to the Brownian motion of a nanoparticle as

$k_{\text {excess }}=\frac{85}{96 \pi^{2}} \frac{\phi K_{B}^{2} T}{r_{p}^{4} \mu}$

Their result represented that the thermal conductivity improvement is proportional to $T / \mu$, where $T$ is the temperature $(K)$ and $\mu$ is viscosity (Pa.s). They also found that the Brownian motion contribution to the enhancement of thermal conductivity of nanoparticle is on the order of $10^{-15} \mathrm{~W} / \mathrm{mK}$ at temperature of $320 \mathrm{~K}$. Therefore, the contribution of the Brownian motion is negligible in comparison with the value of thermal conductivity of base fluid (water). 
Vasu et al. [42] have developed two correlations for the effective thermal conductivity of $\mathrm{Al}_{2} \mathrm{O}_{3}$-water and $\mathrm{Cu}$-water nanofluids by using experimental data taken from literature. Their models consider the effects of temperature, volume fraction and nanoparticle size as

$$
\begin{aligned}
& \frac{k_{n f}}{k_{b f}}=\left(\frac{1}{v_{p}} \sqrt{\frac{18 K_{B} T}{\pi \rho_{p} d_{p}}}\right) \phi^{0.05}\left(\frac{k_{p}}{k_{b f}}\right)^{0.2324} \\
& \frac{k_{n f}}{k_{b f}}=0.74\left(\frac{1}{v_{p}} \sqrt{\frac{18 K_{B} T}{\pi \rho_{p} d_{p}}}\right) \phi^{0.05}\left(\frac{k_{p}}{k_{b f}}\right)^{0.2324}
\end{aligned}
$$

Equations (32) and (33) are applicable for $\mathrm{Al}_{2} \mathrm{O}_{3}$-water and $\mathrm{Cu}$-water nanofluids, respectively. Although their proposed correlations were be able to predict the effective thermal conductivity of nanofluids very well, but they are valid only for the nanofluids whose data were used to formulate the correlation and in the range of the data.

Jain et al. [43] used the Brownian dynamic simulation technique coupled with the GreenKubo model to calculate the effective thermal conductivity of nanofluids by considering the effect of various parameters. They consist of particles concentration ranging from 0.5 to 3 vol. \%, particle size ranging from 15 to $150 \mathrm{~nm}$, and temperature ranging from 290 to $320 \mathrm{~K}$. The effect of base fluid hydrodynamic interactions was considered through a positiondependent interparticle friction tensor. It was also shown that the simulation based on $\mathrm{N}$ coupled Langevin equations is able to involve the effects of different parameters such as particle size, particle concentration, and temperature of the fluid on the effective thermal conductivity of nanofluids. A combined parallel model was used for the calculation of the effective thermal conductivity due to the assumption that thermal conduction caused by the motion of nanoparticles and the base fluid molecules occurs in parallel as

$$
k_{e f f}=\phi k_{p}+(1-\phi) k_{b f}
$$

where $k_{p}$ is the thermal conductivity owing to the Brownian motion of the nanoparticles and calculated by using the Green-Kubo relation as

$$
k_{p}=\frac{1}{K_{B} T^{2} V} \sum_{j=0}^{i}\left(\frac{1}{3(i-j)} \sum_{i i=0}^{i=j} Q(i i \Delta t) \cdot Q[(i i+j) \Delta t]\right) \Delta t
$$

where $T$ is the temperature, $V$ is the volume of the domain, $i$ is the number of time steps used in the simulation and $\Delta t$ is the time step. They also concluded that their model can predict the effective thermal conductivity of nanofluids properly which the Brownian motion of the particles is the key mechanism for the enhancement in the thermal conductivity of nanofluids.

Jung and Yoo [44] developed a model to predict the thermal conductivity of nanofluids by using the kinetic theory in order to describe the contribution of the Brownian motion. They also considered the contribution of the interparticle interaction due to the existence of the 
electrical double layer (EDL). Their model is a modification of Maxwell conventional conductivity model by adding Brownian motion and electrical double layer effects. Therefore, the model can account various factors including temperature, particle size, volume fraction, the Brownian motion and interparticle interaction as follows

$$
k_{\text {eff }}=k_{\text {Maxwell }}+k_{\text {Brownian }}\left(1+\frac{k_{E D L}}{k_{\text {Brownian }}}\right)
$$

Where $k_{\text {Brownian }}$ is the thermal conductivity due to the Brownian motion and $k_{E D L}$ is the thermal conductivity due to the electrical double layer which were expressed, respectively as

$$
\begin{aligned}
& k_{\text {Brownian }}=\frac{N l_{p} c_{v}}{3} \frac{K_{B} T}{3 \pi \mu d_{p} l_{b f}} \\
& k_{E D L}=\frac{N l_{p} c_{v}}{3} \sqrt{\frac{\Gamma q^{2} l_{p}}{\varepsilon_{b f} m_{p}\left(r_{p} \phi^{-\frac{1}{3}}\right)^{2}}}
\end{aligned}
$$

where $\Gamma$ is Coulomb constant $\left(9 \times 10^{9} \mathrm{Nm}^{2} / \mathrm{C}^{2}\right)$ and $q$ is electric charge $(C)$. It was shown that the model is applied to Au-water nanofluids satisfactorily with respect to temperature, volume fraction and particle size. In the case of high concentration of $\mathrm{Al}_{2} \mathrm{O}_{3}$-water nanofluids, the effect of the interparticle interaction is more on enhancing the thermal conductivity due to EDL.

Murshed et al. [45] developed a combined static and dynamic mechanisms-based model to predict the effective thermal conductivity of nanofluids. Their model can count most of the possible parameters such as particle size, nanolayer, particle movements, interactions and surface chemistry of nanoparticles. Furthermore, it was shown that dynamic mechanisms such as particle Brownian motion, particle interactions and surface chemistry are significant when there are smaller-sized nanoparticles as well as low volume fractions. However, the major contributions to the enhancement are from static mechanisms. The model was considered to be the result of both static and dynamic mechanisms as follows 


$$
\begin{aligned}
& k_{e f f-n f}=\left\{k_{b f} \frac{\phi_{p} \omega\left(k_{p}-\omega k_{b f}\right)\left[2\left(1+\frac{\delta_{n l}}{2 r_{p}}\right)^{3}-\left(1+\frac{\delta_{n l}}{r_{p}}\right)^{3}+1\right]+\left(k_{p}+2 \omega k_{b f}\right)\left(1+\frac{\delta_{n l}}{2 r_{p}}\right)^{3}\left[\phi_{p}\left(1+\frac{\delta_{n l}}{r_{p}}\right)^{3}(\omega-1)+1\right]}{\left(1+\frac{\delta_{n l}}{2 r_{p}}\right)^{3}\left(k_{p}+2 \omega k_{b f}\right)-\left(k_{p}-\omega k_{b f}\right) \phi_{p}\left[\left(1+\frac{\delta_{n l}}{2 r_{p}}\right)^{3}-\left(1+\frac{\delta_{n l}}{r_{p}}\right)^{3}+1\right]}\right\} \\
& +\left\{\begin{array}{l}
\phi_{p}^{2}\left(1+\frac{\delta_{n l}}{2 r_{p}}\right)^{6} k_{b f}\left[3\left(\frac{k_{c p}-k_{b f}}{k_{c p}+2 k_{b f}}\right)^{2}+\frac{3}{4}\left(\frac{k_{c p}-k_{b f}}{k_{c p}+2 k_{b f}}\right)^{2}+\frac{9}{16}\left(\frac{k_{c p}-k_{b f}}{k_{c p}+2 k_{b f}}\right)^{3}\left(\frac{k_{c p}+k_{b f}}{2 k_{c p}+3 k_{b f}}\right)\right] \\
+\frac{3}{2^{6}}\left(\frac{k_{c p}-k_{b f}}{k_{c p}+2 k_{b f}}\right)^{4}+\ldots
\end{array}\right\} \\
& +\left\{\frac{1}{2} \rho_{c p} c_{c p} d_{p}\left[\sqrt{\frac{3 K_{B} T\left[1-1.5\left(1+\frac{\delta_{n l}}{r_{p}}\right)^{3} \phi_{p}\right]}{2 \pi \rho_{c p}\left(1+\frac{\delta_{n l}}{r_{p}}\right)^{3} r_{p}^{3}}}+\frac{G_{T}}{6 \pi \mu\left(1+\frac{\delta_{n l}}{r_{p}}\right) r_{p} d_{p}}\right]\right\}
\end{aligned}
$$

The significant features of the proposed model were summarized as follows:

- The model was developed by considering nanoparticles with a thin interfacial layer together with their static and dynamic mechanisms in the base fluid.

- The second term on the right hand side of Eq. (39) is stand for the interactions between pairs of spherical nanoparticles in a stationary suspension.

- The third term on the right hand side of Eq. (39) represents the effect of particle Brownian motion, particle surface chemistry and inter-particle interactions for $\phi_{p}>0.005$. This part is not applicable when $\phi_{p}<0.005$ because at such a small volume fraction, the interparticle separation distance is too large to cause any interactions through the Brownian and potential forces of particles.

- In case of no interaction between pairs of nanoparticles and the interfacial layer, the static part of the model reduces to the Maxwell model and when $\phi_{p}=0$ the entire model reduces to $k_{b f}$.

Emami-Meibodi et al. [46, 47] offered a simple new model in order to count the Brownian motion. The particle size did not involve in their model; therefore, they mentioned that their model could work for any suspension including microparticles and nanoparticles. However, this is approved that at the same volume fraction and condition, the effective thermal conductivity of a nanofluid with smaller particle will be more [48].

Mehta et al. [49] proposed a theoretical model to predict the thermal conductivity of nanofluids at low volume fraction of particles. The heat transfer contributions from 
liquid/solid conduction and micro-convection around particles were considered separately using thermal resistance modeling. The diffusion velocities of particles due to Brownian motion were used for the modeling of micro-convection around the nanoparticles. In their proposed model, the particles were assumed to be spherical and mono-dispersed without agglomeration in the liquid. The model was validated against a variety of experimental data available in the literature for alumina, copper, copper oxide and titanium oxide based nanofluids for different concentration of nanoparticles.

Xiao et al. [50] developed an analytical expression for effective thermal conductivity of nanofluids by considering the effect of heat convection between nanoparticles and liquids due to the Brownian motion of nanoparticles in fluids. The correlation of effective thermal conductivity of nanofluids was given by taking into account the fractal distribution of nanoparticles. The model was expressed as a function of the thermal conductivities of the base fluids and the nanoparticles, the average diameter of nanoparticles, the nanoparticle volume concentration, the fractal dimension of nanoparticles and physical properties of fluids.

Babaei et al. [51] developed equilibrium molecular dynamics simulations in order to investigate the role of micro-convection on the thermal conductivity of well-dispersed nanofluids. Their results were shown that while individual convective terms in the heat current expression are significant, they essentially cancel each other. Consequently, microconvection does not contribute noticeably to the thermal conductivity as well as the predicted thermal conductivity enhancements are consistent with the effective medium theory.

\section{Nanolayer}

Nanofluid structure consists of solid nanoparticles, solid-like liquid layers (known as nanolayers) and a base fluid. An interfacial thermal resistance is present at interfaces of different components of mixtures, which is known as the Kapitza resistance. It has long been known that liquid molecules close to a solid surface form a layered solid-like structure [52, 53], but little is known about the thermal properties of this nanolayer and the connection of this layer with the base fluid and the solid. According to $\mathrm{Yu}$ et al. [53], the layered molecules are in an intermediate physical state between a solid and a base fluid. Therefore, the solid-like nanolayer of liquid molecules would be expected to lead to a higher thermal conductivity than that of the base fluid. This means that the solid-like nanolayer acts as a thermal bridge between a solid nanoparticle and a base fluid, and so it is the key to enhancing thermal conductivity [54].

$\mathrm{Yu}$ and Choi [54] modified the Maxwell equation to calculate the effective thermal conductivity of solid/liquid suspensions including the effect of the nanolayer. They assumed that the nanolayer around each particle could be combined with the particle to form an equivalent particle and because of the particle volume concentration being so small; there is 
no overlap of those equivalent particles. According to Feng et al. [55], this is not realistic because the liquid molecules surrounding the particle surface form the interfacial layer and the concentration of these adsorbed molecules in the interfacial layer is lower than that of the solid particle. Therefore, the interfacial layer thermal conductivity should be lower than that of the solid particles but higher than that of the liquid. Consequently, Feng et al. [55] estimated an upper limit for the effect of the interfacial layer by replacing the thermal conductivity of the nanoparticle $k_{p}$ with an equivalent one $k_{p e}$, namely thermal nanoparticle thermal conductivity in the Maxwell model as:

$$
k_{e f f}=\frac{k_{p e}+2 k_{b f}+2\left(k_{p e}-k_{b f}\right)\left(1+\frac{\delta_{n l}}{r_{p}}\right)^{3} \phi}{k_{p e}+2 k_{b f}-\left(k_{p e}-k_{b f}\right)\left(1+\frac{\delta_{n l}}{r_{p}}\right)^{3} \phi} k_{b f}
$$

with:

$$
k_{p e}=\left[\frac{\left[2\left(1-\frac{k_{n l}}{k_{p}}\right)+\left(1+\frac{\delta_{n l}}{r_{p}}\right)^{3}\left(1+2 \frac{k_{n l}}{k_{p}}\right)\right] \frac{k_{n l}}{k_{p}}}{\left(\frac{k_{n l}}{k_{p}}-1\right)+\left(1+\frac{\delta_{n l}}{r_{p}}\right)^{3}\left(1+2 \frac{k_{n l}}{k_{p}}\right)}\right] k_{p}
$$

The model includes the nanolayer which can predict the presence of a nanolayer with a thickness of less than $10 \mathrm{~nm}$.

A renovated Maxwell model, which was proposed by Yu and Choi [54] in 2003, was limited to suspensions with spherical particles. Yu and Choi [56], in 2004, extended the Hamilton-Crosser model suspensions of non-spherical particles to include the effect of the nanolayer as

$$
k_{e f f}=\left[1+\frac{D_{e s f} \phi_{e}\left(\frac{1}{3} \sum_{j=a, b, c} \frac{k_{p j}-k_{b f}}{k_{p j}+\left(D_{e s f}-1\right) k_{b f}}\right)}{1-\phi_{e}\left(\frac{1}{3} \sum_{j=a, b, c} \frac{k_{p j}-k_{b f}}{k_{p j}+\left(D_{e s f}-1\right) k_{b f}}\right)}\right] k_{b f}
$$

where $D_{e s f}$ is the empirical shape factor $D_{e s f}=3 \Psi^{-\psi}, \psi$ is an empirical parameter depending on the particle sphericity or eccentricity and the particle-to-liquid thermal conductivity ratio and $\Psi$ is the sphericity defined as the ration of the surface area of a sphere, with a volume equal to that of the particle, to the surface area of the particle.

$k_{p j}=\left\{1+\frac{k_{s e}-k_{s l}}{k_{p}\left[V_{r} \cdot d(j, 0)-d(j, v)\right]-k_{s l}\left[V_{r} \cdot d(j, 0)-d(j, v)-V_{r}\right]}\right\} k_{s l}$

$k_{p j}$ is the equivalent thermal conductivities along the axes of the complex ellipsoid in which 
$j(=a, b$ and $c)$ is along the semiaxis directions of the ellipsoid, $k_{s e}$ and $k_{s l}$ are the thermal conductivities of the solid ellipsoid and its surrounding layer, $V_{r}$ is the volumetric ratio and $d(j, v)$ is the depolarization factor.

$\phi_{e}$ is the equivalent volume concentration of complex ellipsoids which is defined as $\phi_{e}=V_{r} \phi$

where $\phi$ is a volume concentration of the solid ellipsoids without the surrounding layer.

This model can predict the thermal conductivity of nanofluids consisting of carbon nanotubes-in-oil. However, it fails to predict the non-linear behaviour of the effective thermal conductivity of general oxide- and metal-based nanofluids. In the new model, they assumed the thermal conductivity of the nanolayer around each particle is the same than that of the nanoparticle, which is not realistic [55].

Xue et al. [57] used non-equilibrium molecular dynamic simulations in which a temperature gradient was imposed, and they determined the thermal resistance of liquid/solid interface. Their simulation indicates that the strength of the bonding between the liquid and the solid atoms plays a key role in determining the interfacial thermal resistance. They also found that the functional dependence of the thermal resistance on the strength of the liquid/solid interactions reveals two distinct regimes. The two regimes [58] are exponential dependence for weak bonding and power law dependence for strong bonding. These two regimes of the Kapitza resistance have profound implications for understanding and designing the thermal properties of nanolayers.

Xue [58] considered the effect of the nanolayer between the solid particle and the base fluid in nanofluids. Xue presented a new model for the effective thermal conductivity for nanofluids based on the Maxwell model and average polarisation theory. However, in his model, it is not clear how to determine the depolarisation factor component for the different shapes of particles, and also the thermal conductivity of nanolayers cannot be determined [57]. Another problem with his model is that the predicted thermal conductivity values are matched with experimental data by considering the larger nanolayer thickness, which is not realistic. Later Yu and Choi [56] showed that Xue's model gave far higher values of thermal conductivity than those given in his paper because Xue used incorrect parameters when comparing his model with that of carbon nanotube-in-oil experimental data. Thus the validity and accuracy of Xue's model are yet to be established.

Xie et al. [59] assumed that the interfacial structures formed by liquid molecule layering might play an important role. They investigated the impact of these nanolayers on the effective thermal conductivity of nanofluids and also developed an expression for calculating the enhanced thermal conductivity of nanofluids. They proposed a new formula for the effective thermal conductivity derived from the general solution of the heat conduction equation in spherical coordinates. Although by that time, there was no available expression 
for calculating the thermal conductivity of nanolayers, they proposed a new model for the thermal conductivity of a nanolayer as well. For this purpose, they assumed that the thermal conductivity variation in a nanolayer is linear and derived the following equation for the thermal conductivity of a nanolayer:

$$
k_{n l}=\frac{k_{b f}\left[\frac{k_{p}}{k_{b f}}\left(1+\frac{\delta_{n l}}{r_{p}}\right)-1\right]^{2}}{\left(\left[\frac{k_{p}}{k_{b f}}\left(1+\frac{\delta_{n l}}{r_{p}}\right)-1\right]-\frac{\delta_{n l}}{r_{p}}\right) \ln \left(1+\left[\frac{k_{p}}{k_{b f}}\left(1+\frac{\delta_{n l}}{r_{p}}\right)-1\right]\right)+\frac{\delta_{n l}}{r_{p}}\left[\frac{k_{p}}{k_{b f}}\left(1+\frac{\delta_{n l}}{r_{p}}\right)-1\right]}
$$

Therefore, the average thermal conductivity of a nanolayer depends on the thermal conductivity of the fluid, the reduced thermal conductivity of the nanoparticle and the ratio of the nanolayer thickness to the original particle radius. They also proposed a formula for the effective thermal conductivity of a nanofluid by applying Fourier's law of heat conduction based on the assumption that a nanofluid is statistically homogeneous and isotropic. It is obtained as

$$
\frac{k_{e f f}-k_{b f}}{k_{b f}}=3 \Theta \phi_{e f f}+\frac{3 \Theta^{2} \phi_{e f f}^{2}}{1-\Theta \phi_{e f f}}
$$

with

$$
\Theta=\frac{\left(\frac{k_{n l}-k_{b f}}{k_{n l}+2 k_{b f}}\right)\left[\left(1+\frac{\delta_{n l}}{r_{p}}\right)^{3}-\left[\frac{\left(k_{p}-k_{n l}\right)\left(k_{b f}+2 k_{n l}\right)}{\left(k_{p}+2 k_{n l}\right)\left(k_{b f}-k_{n l}\right)}\right]\right]}{\left(1+\frac{\delta_{n l}}{r_{p}}\right)^{3}+2\left[\frac{\left(k_{n l}-k_{b f}\right)\left(k_{p}-k_{n l}\right)}{\left(k_{n l}+2 k_{b f}\right)\left(k_{p}+2 k_{n l}\right)}\right]}
$$

This equation is the proposed model deduced for evaluating the effect of the nanolayer on the effective thermal conductivity of nanoparticle/fluid mixtures. In order to check the for validity, they used experimental data of $\mathrm{Cu}$-in-EG, $\mathrm{CuO}$-in-EG, and alumina-in-water and the results show that the proposed model predicts these experimental data quite well. However, similar to the $\mathrm{Yu}$ and Choi $[54,56]$ and Xue [58] models, this empirical model has to be fitted with experimental data by adjusting two fitting parameters. They did not also consider any dynamic mechanism like Brownian motion.

Leong et al. [60] also proposed a new model for the effective thermal conductivity of a nanofluid according to the heat conduction in a nanofluid based on Fourier's law for considering the effect of the interfacial layer as

$$
k_{e f f}=\frac{\left(k_{p}-k_{n l}\right) \phi_{n l} k_{n l}\left[2\left(1+\frac{\delta_{n l}}{2 r_{p}}\right)^{3}-\left(1+\frac{\delta_{n l}}{r_{p}}\right)^{3}+1\right]+\left(k_{p}+2 k_{n l}\right)\left(1+\frac{\delta_{n l}}{2 r_{p}}\right)^{3}\left[\phi_{n l}\left(1+\frac{\delta_{n l}}{r_{p}}\right)^{3}\left(k_{n l}-k_{b f}\right)+k_{b f}\right]}{\left(1+\frac{\delta_{n l}}{2 r_{p}}\right)^{3}\left(k_{p}+2 k_{n l}\right)-\left(k_{p}-k_{n l}\right) \phi_{n l}\left[\left(1+\frac{\delta_{n l}}{2 r_{p}}\right)^{3}+\left(1+\frac{\delta_{n l}}{r_{p}}\right)^{3}-1\right]}
$$


where $\phi_{n l}=\phi_{p}\left[\left(1+\frac{\delta_{n l}}{r_{p}}\right)^{3}-1\right]$

They compared their model with some experimental data of alumina-in-DI water, alumina-in-EG, $\mathrm{CuO}$-in-DI water and $\mathrm{CuO}$-in-EG and concluded that the present model can predict the effective thermal conductivity of nanofluids better than previous models. The improved results come from the point where the temperature gradient at the boundary of the nanolayer is discontinuous. However, a limitation of their model is that they have to set the thermal conductivity and thickness of the nanolayer to predict the experimental data, and they also assumed that the particles are apart and no interaction occurs between them.

Yu et al. [54] suggested a new model for the thermal conductivity of nanofluids. The proposed model is expressed as a function of the thickness of a nanolayer, the nanoparticle size, the nanoparticle volume fraction, and the thermal conductivities of the suspended nanoparticles and base fluid. Their model is in good agreement with the experimental data

Tillman and Hill [61] proposed a revised procedure to determine the nanolayer thickness and the thermal conductivity profile inside a nanolayer. They explained that there was no known procedure to properly calculate the nanolayer thickness and all previous investigators just chose the nanolayer thickness to match their results with the experimental data. They assumed that the thermal conductivity profile within the nanolayer is given as

$k_{n l}(r)=X(1-Y r)^{m}$

where $X$ and $Y$ are parameters determined from the continuity of thermal conductivity at the interface, $m$ is a power law exponent and $r$ is spherical coordinate radius. To calculate the temperature profile inside the nanolayer, they assumed the steady-state heat conduction in spherical coordinates with axial symmetry and realised that the temperature profile inside the nanolayer can be obtained by using the separation of variable method as

$T_{n l}(r, \theta)=A(r) \cos \theta=\left[E y_{1}(r)+F y_{2}(r)\right] \cos \theta$

where $E$ and $F$ are parameters that should be determined through the relevant boundary conditions for temperature, and $y_{1}(r)$ and $y_{2}(r)$ are the non-linear independent solutions of the second-order differential equation of

$\frac{d^{2} A}{d r^{2}}+\left(\frac{2}{r}+\frac{1}{k} \frac{d k}{d r}\right) \frac{d A}{d r}-\frac{2}{r^{2}} A=0$

They also calculated the critical nanolayer thickness by solving the following equation, 


$$
\frac{\frac{d}{d r}\left[\frac{y_{1}\left(r_{p}\right)}{r_{p}}\right]}{\frac{d}{d r}\left[\frac{y_{2}\left(r_{p}\right)}{r_{p}}\right]}=\frac{\frac{d}{d r}\left[R^{2} y_{1}(R)\right]}{\frac{d}{d r}\left[R^{2} y_{2}(R)\right]}
$$

The calculated nanolayer thicknesses for alumina-in-EG and $\mathrm{CuO}$-in-water nanofluids are approximately $19 \%$ and $22 \%$ of the corresponding nanoparticle radius respectively, which are consistent with data used in other studies. They also compared the results of their model with alumina-in-EG, CuO-in-EG, $\mathrm{Cu}$-in-oil, $\mathrm{CuO}$-in-water experiments and their results show good agreement with these experimental data. However, in their model, three functions for thermal conductivity of nanolayers were tested but just one of them produced stable results. This means that their model needs more validation for determining an accurate function of the nanolayer thermal conductivity.

Li et al. [62] investigated the molecular layer of liquid/solid interfaces of a nanofluid with an equilibrium molecular dynamic simulation method. They assumed that the nanoparticles are spherical and developed their model by tracking the positions of the nanoparticle and the liquid atoms around the nanoparticles. They estimated that the thickness of the nanolayer is approximately $0.5 \mathrm{~nm}$ and will move with the Brownian motion of the nanoparticle. Although this finding is very important to the understanding of the thermal property of a nanofluid, however, their investigation is not complete. Their nanofluid consisted of $1.5 \%$ (volume fraction) of copper nanoparticles in an argon base fluid; therefore, it needs to be evaluated for different cases.

Zhou and Gao [63] investigated the effect of interfacial nanolayers and the mutual interaction of nearest-neighbouring inclusions on the effective thermal conductivity of nanofluids. Firstly differential effective dipole approximation was generalized to obtain the equivalent thermal conductivity of the coated nanoparticles with graded nanolayers. The multiple image method was then employed to investigate the effect of mutual interaction between nanoparticles on the thermal conductivity of nanofluids. The dependence of effective thermal conductivity on volume fraction, radius of nanoparticles, thickness of the nanoshell, and thermal conductivity of the constituents was shown by an analytical correlation as

$$
\frac{k_{e f f}}{k_{b f}}=1+\frac{3 \phi_{t} b\left[\frac{P_{L}+2 P_{T}}{3 P_{0}}\right]}{1-\phi_{t} b\left[\frac{P_{L}+2 P_{T}}{3 P_{0}}\right]}
$$

where $b=\left[\bar{k}\left(r_{p}+\delta_{n l}\right)-k_{b f}\right] /\left[\bar{k}\left(r_{p}+\delta_{n l}\right)+2 k_{b f}\right]$ is a dipole factor and $\phi_{t}$ is the total volume fraction of the coated particles which include both original nanoparticles and graded nanolayers, expressed as 
$\phi_{t}=\frac{4}{3} \pi\left(r_{p}+\delta_{n l}\right)^{3} n_{v}=\phi_{0}\left(1+\frac{\delta_{n l}}{r_{p}}\right)^{3}$

where $\phi_{0}=(4 / 3) \pi r_{p}^{3} n_{v}$ is the original volume fraction of nanoparticles and $n_{v}$ is the number of complicated particles per volume.

Lin et al. [64] conducted a molecular dynamics (MD) simulation for thermal conductivity of $\mathrm{Cu}$ - EG (ethylene glycol) by considering the role of particle/fluid interface effect as main mechanism of the thermal conductivity enhancement. Layer-Maxwell model for effective thermal conductivity was developed by taking into account the distinct thermal conductivity in the nanolayers around nanoparticle obtained from MD simulations.

Although the nanolayer effect and its mechanism play an important role in the thermal conductivity enhancement of nanofluids, the experiments and simulations [52, 53 and 62] showed that the thickness of the nanolayer is only in the order of a few atomic distances $(0.5$ to $1 \mathrm{~nm}$ ). Thus it does not seem to be the only factor for the enhancement [13].

\section{Clustering}

There are two methods for producing nanofluids: the one-step direct evaporation method represents the direct formation of the nanoparticles inside the base fluids, and the two-step method represents the formation of nanoparticles and subsequent dispersion of the nanoparticles in the base fluid. In the two-step method, the nanoparticles are separately produced. Thereafter, when the nanoparticles are being dispersed into the base fluid it should be treated with various physical treatment techniques to ensure a homogeneous dispersion. Different types of physical treatment devices that are being used are the stirrer, the ultrasonic bath, the ultrasonic disruptor and the high-pressure homogeniser [65]. These methods were used for preventing the nanoparticles to get agglomerated at the first step of nanofluid production because the nanoparticles as powder get agglomerated to each other very soon. When the nanofluid is treated by sonication (high frequency sound waves typically used to aid the dispersion of nanoparticles in a liquid) or other physical techniques, the cluster breaks into primary nanoparticles [66]. There have been some works on the effect of sonication time on the thermal conductivity of nanofluids [67].

Wang et al. [68], proposed a new model for the thermal conductivities of nanofluids based on the effective medium approximation and the fractal theory for the description of nanoparticle clusters and its radial distributions. The size effect and the surface adsorption of nanoparticles (nanolayer) are taken into consideration. Their model predicts the data of $\mathrm{CuO}-$ in-water quite well, but their model is yet to be validated with more experimental results.

After producing stable nanofluids, nanoparticles in nanofluid get often aggregated, because of the collision and forces between them such as the Van der Waals' forces. This occurs usually in fluids with higher concentrations and by the time nanofluids form a cluster. 
This aggregate structure acts like a local percolation structure and therefore, adds to the effective thermal conductivity enhancement of nanofluids locally, however, losing the homogeneity as well as the stability of the nanofluid.

By creating paths of lower thermal resistance, clustering of particles into percolating patterns would have a major effect on the effective thermal conductivity. Although percolating structures cannot be set up, local clustering is possible and indeed has been observed experimentally. Within such a cluster, heat can move very rapidly. The volume fraction of the highly conductive phase is larger than the solid volume and may significantly increase the thermal conductivity.

Karthikeyan et al. [66] studied effect of clustering on the thermal conductivity of $\mathrm{CuO}$ nanoparticles dispersed into water experimentally. They had shown that the cluster size has a significant effect on the thermal conductivity of $\mathrm{CuO}$-Water nanofluids and the thermal conductivity of nanofluid decrease with elapsed time due to clustering of $\mathrm{CuO}$ nanoparticles. Furthermore, they indicated that the finer particle size and mono-dispersity of nanoparticles causes larger enhancement in thermal conductivity of nanofluids. They also noted that in general, clustering may exert a negative effect on heat transfer enhancement. The nanoclusters are likely to settle in the fluid due to their larger mass that results in a particle gradient in the fluid, particularly at low volume fractions, by settling small particles out of the liquid and creating large regions of particle free-liquid with high thermal resistances. The particle-free zones have higher thermal resistances compared with the particle-rich zone. The suppression of clustering of the nanoparticles is also very important for designing effective heat transfer fluids. There are some reports on the formation of clusters and aggregates in the fluid, which enhances the thermal conductivity of the fluid; however, some others mention that the thermal conductivity decreases with elapsed time due to the clustering of nanoparticles.

According to the report of Wang et al. [68] in 2003, these cluster structures act like local percolation structures and therefore add to the effective thermal conductivity enhancement of nanofluids [68] (this is contrary to the observation of Karthikeyan et al. [66]). They proposed a method for modelling the effective thermal conductivity of nanofluids based on the effective medium approximation and the fractal theory for the description of nanoparticle clusters and its radial distributions. They modified the Maxwell model by taking into account the size effect and the surface adsorption of nanoparticles. Their model, however, requires the thermal conductivity of particle clusters and their radius distribution to be determined numerically [69]. Their fractal model predicts well the trend for variation of the effective thermal conductivity with diluted suspensions of nanoparticles and fits the experimental data for $\mathrm{CuO}$-in-DI water successfully. In addition, this model has yet to be validated with experimental results. The other model was proposed by Prasher et al. [70], and shows that the thermal conductivity of nanofluids based purely on conduction phenomenon can be significantly enhanced as a result of the aggregation of the nanoparticles. These two groups of researchers believe that the cluster effect can enhance the thermal conductivity of nanofluids because the heat transport can be much faster along the backbone of the clusters. 
The important thing is that the cluster sizes are critical to the thermal performance of nanofluids. When the cluster sizes increase, the nanoclusters are likely to settle in the fluids due to larger mass, which results in gradients in the particle concentrations. Therefore, the cluster size should not be more than its critical size for this purpose. There are two major methods to make the attractive force between particles balanced, and hence to prevent particle aggregation. These two methods are electrostatic stabilisation and steric stabilisation.

Prasher et al. [71], by using the effective medium theory, showed that the thermal conductivity of nanofluids can be significantly enhanced by the aggregation of nanoparticles into clusters. They claimed that the observed thermal conductivity of nanofluids can be explained by aggregation kinetics. Their predictions of the effective medium theory were in excellent agreement with detailed numerical calculations on model nanofluids involving fractal clusters and showed the importance of cluster morphology on thermal conductivity enhancements. It was also reported that colloidal chemistry played a significant role in determining the thermal conductivity of nanofluids.

Feng et al. [55] proposed a new model for the effective thermal conductivity of nanofluids by considering the nanolayer and nanoparticle aggregation. The model is expressed as a function of the thickness of the nanolayer, the nanoparticle size, the nanoparticle volume fraction and the thermal conductivities of the suspended nanoparticles and the base fluid. For determining the effect of aggregation, they divided the aggregation into two parts: the first is the coherent fluid and the other is a quarter of the column. The column also includes two parts: the touching particles and the base fluid. They used the thermal-electrical analogy technique and the one-dimensional heat conduction model for calculating. The theoretical predictions of the effective thermal conductivities of nanofluids are shown to be in good agreement with experimental data of $\mathrm{CuO}$-in-water, alumina-in-water, $\mathrm{CuO}$-in-EG, and alumina-in-EG.

Agop et al. [72] investigated the effects of nanoparticle clustering on the heat transfer in nanofluids using the scale relativity theory. They found that in the one-dimensional differentiable case, a non-autonomous regime implies a relation between the radius and growth speed of the cluster, while a quasi-autonomous regime requires El Naschie's theory through the cluster-cluster coherence (El Naschie global coherence). They offered a hybrid mathematical procedure in their work, but they did not offer any practical correlation in order to modify the thermal conductivity of nanofluids.

Okeke et al. [73] conducted a numerical investigation into thermal conductivity of water based nanofluids of $\mathrm{Al}_{2} \mathrm{O}_{3}, \mathrm{CuO}$ and $\mathrm{TiO}_{2}$ considering the particle clustering and interfacial layer thickness as effective parameters. Regardless the type of nanofluid, it has been shown that the mode of aggregation plays a major rule in thermal enhancement by influencing the aggregation rate and compactness of the aggregates. In their study they showed the sensitiveness of thermal conductivity to particle aggregation as a possible mechanism for thermal enhancement and relations between aggregation mode, aggregate size and compactness of the aggregates and thermal enhancement of the surrounding nanofluid. 
Witharana et al. [74], studied aggregation and settling behaviour of nanofluids near their isoelectric points by using small angle X-ray scattering (SAXS) experiments and optical microscopy for a rapidly settling poly-disperse spherical alumina $\left(\mathrm{Al}_{2} \mathrm{O}_{3}\right)$ nanoparticles in the size range of 10-100 $\mathrm{nm}$ were dispersed in water at room temperature. Two settling regime were observed regarding photographic studies and the corresponding settling curve; one showing the settling of very large $(\sim 22 \mu \mathrm{m})$ objects and the second one showing a slower settling rate of relatively smaller $(\sim 6 \mu \mathrm{m})$ objects. They also indicated that using the SAXS technique provided valuable information for this unstable suspension which was not possible to obtain from any existing mechanism. Optical microscopy images were also produced on drying and dried droplets extracted from the suspension at various times. Dried deposits showed the rapid decrease in the number of very large particles with time which qualitatively validates the SAXS prediction, and therefore its suitability as a tool to study unstable polydisperse colloids.

\section{Hybrid model and other effects}

There is a lack of reported research on hybrid combined models for the effective thermal conductivity that takes into consideration all major mechanisms plus other important recognized effects like particle settling down time [75-78], temperature [79], $\mathrm{pH}$ [80-82], dispersion [83] and the particle size effect on surface contact of liquid/particle interaction [41, 84-86]. However, the following models are valuable because they included some of these effects.

Avsec [87] developed a combined model based on statistical nanomechanics. His model accounts for influences such as the formation of the nanolayer around nanoparticles and the Brownian motion. He modified the model of Yu and Choi [54] for the nanolayer part of his model by expressing the effective volume fraction as

$$
\phi_{\text {eff }}=\phi\left(1+\frac{\delta_{n l}}{r_{p}}\right)^{3}
$$

However, he assumed that the equivalent thermal conductivity of the equivalent particles had the same value as the thermal conductivity of the particle. He also modified Prasher's equation [88] for influence of Brownian motion and then offered the thermal conductivity for nanofluids as

$$
k_{e f f}=k_{b f}\left[\frac{k_{p}+\left(\frac{3}{\Psi}-1\right) k_{b f}-\left(\frac{3}{\Psi}-1\right) \phi_{e f f}\left(k_{b f}-k_{p}\right)}{k_{p}+\left(\frac{3}{\Psi}-1\right) k_{b f}+\phi_{e f f}\left(k_{b f}-k_{p}\right)}\right]\left(1+C_{f t} \operatorname{Re}^{O_{c o}} \operatorname{Pr}^{S_{c o}}\right)
$$

He compared his model with the experimental works from literature for copper nanoparticles $(10 \mathrm{~nm})$ in an ethylene-glycol base and also for aluminium oxide nanoparticles in a water 
base. Although he found good agreement with those two cases, working with the equation including fitting parameter is hard in general.

Murshed et al. [45] offered a combined model, which included the effects of particle size, nanolayer, Brownian motion, and particle surface chemistry and interaction potential which are the static and dynamic mechanisms responsible for the enhanced effective thermal conductivity of nanofluids. They divided the effective thermal conductivity into two parts consisting of the static-based and the dynamic part (particle Brownian motion, particle surface chemistry and interparticle interactions), i.e. $k_{\text {eff }}=k_{\text {static }}+k_{\text {dynamic }}$, or

$k_{e f f-n f}=\left\{k_{b f} \frac{\phi_{p} \omega\left(k_{p}-\omega k_{b f}\right)\left[2\left(1+\frac{\delta_{n l}}{2 r_{p}}\right)^{3}-\left(1+\frac{\delta_{n l}}{r_{p}}\right)^{3}+1\right]+\left(k_{p}+2 \omega k_{b f}\right)\left(1+\frac{\delta_{n l}}{2 r_{p}}\right)^{3}\left[\phi_{p}\left(1+\frac{\delta_{n l}}{r_{p}}\right)^{3}(\omega-1)+1\right]}{\left(1+\frac{\delta_{n l}}{2 r_{p}}\right)^{3}\left(k_{p}+2 \omega k_{b f}\right)-\left(k_{p}-\omega k_{b f}\right) \phi_{p}\left[\left(1+\frac{\delta_{n l}}{2 r_{p}}\right)^{3}-\left(1+\frac{\delta_{n l}}{r_{p}}\right)^{3}+1\right]}\right\}$

$+\left\{\phi_{p}^{2}\left(1+\frac{\delta_{n l}}{2 r_{p}}\right)^{6} k_{b f}\left[3 \Lambda^{2}+\frac{3 \Lambda^{2}}{2^{2}}+\frac{3^{2} \Lambda^{3}}{2^{4}}\left(\frac{k_{c p}+k_{b f}}{2 k_{c p}+3 k_{b f}}\right)+\frac{3 \Lambda^{4}}{2^{5}}+\ldots\right]\right\}$

$+\left\{\frac{1}{2} \rho_{c p} c_{c p} d_{p}\left[\sqrt{\frac{3 K_{B} T\left[1-1.5\left(1+\frac{\delta_{n l}}{r_{p}}\right)^{3} \phi_{p}\right]}{2 \pi \rho_{c p}\left(1+\frac{\delta_{n l}}{r_{p}}\right)^{3} r_{p}^{3}}}+\frac{G_{T}}{6 \pi \mu\left(1+\frac{\delta_{n l}}{r_{p}}\right) r_{p} d_{p}}\right]\right\}$

where $k_{c p}=k_{n l}\left[\frac{2\left(k_{p}-k_{n l}\right)+\left(1+\frac{\delta_{n l}}{r_{p}}\right)^{3}\left(k_{p}-k_{n l}\right)}{\left(k_{n l}-k_{p}\right)+\left(1+\frac{\delta_{n l}}{r_{p}}\right)^{3}\left(k_{p}+2 k_{n l}\right)}\right], \Lambda=\frac{k_{c p}-k_{b f}}{k_{c p}+2 k_{b f}}$

The third term on the right-hand side of equation (57) takes into account the effect of the dynamic part on effective thermal conductivity, which is applicable for nanoparticle volume fractions more than $0.5 \%$. They compared their model with their experiments as well as with experiments in literature consisting of $\mathrm{TiO}_{2}(15 \mathrm{~nm}) / \mathrm{DIW}$-based, $\mathrm{Al}_{2} \mathrm{O}_{3} / \mathrm{DIW}$-based, $\mathrm{Al}_{2} \mathrm{O}_{3}$ /water-based, $\mathrm{CuO}$ /water-based and $\mathrm{Fe}_{3} \mathrm{O}_{4}$ /water-based nanofluids. They found a good agreement. They assumed that the nanolayer thermal conductivity $(\omega)$, can be between 1.1 and 2.5 without a sensible logic procedure, however, this model needs to be validated in the case of varying each parameter (particle size, nanolayer, Brownian motion, interaction and particle surface chemistry) when the others stay constant with proper experiments. However, this model could not take into consideration the effect of clustering or settling time.

Corcione $[89,90]$, offered an empirical relation for the effective thermal conductivity of nanofluids based on literature experimental data with a $1.86 \%$ standard deviation of error. His 
simple correlation can count the influence of the nanoparticle volume fraction, the temperature and the nanoparticle diameter as

$\frac{k_{e f f}}{k_{b f}}=1+4.4 \operatorname{Re}^{0.4} \operatorname{Pr}^{0.66} \phi^{0.66}\left(\frac{T}{T_{f r}}\right)^{10}\left(\frac{k_{p}}{k_{b f}}\right)^{0.03}$

where $\operatorname{Re}$ is the nanoparticle Reynolds number, which is defined as

$\operatorname{Re}=\frac{2 \rho_{b f} K_{B} T}{\pi \mu_{b f}^{2} d_{p}}$

and all the physical properties must be calculated at the nanofluid temperature $T$. Although he compared his model with the experimental data of literature, the effect of the nanolayer is not taken into consideration in the equation and it needs to be investigated experimentally.

Li et al. [91] investigated into the mechanisms of thermal conductivity of nanofluids, including particle agglomeration, Brownian motion effects and viscosity as well as the effect of temperature. Their results showed that Brownian motion is not enough to describe the temperature dependence of the thermal conductivity of nanofluids. They indicated that the change of particle agglomeration and viscosity with temperature are also important factors. The reduction of the particle surface energy as a result of temperature increase would decrease the agglomeration of nanoparticles, and the reduction of viscosity would improve the Brownian motion. By taking into account the effects of the nano-scale, the effects of the interfacial interaction between nanoparticles and liquid as well as Brownian motion, the model was expressed as

$k_{e f f}=\frac{k_{p n}+2 k_{b f}-2 \phi_{e f f}\left(k_{b f}-k_{p n}\right)}{k_{p n}+2 k_{b f}+\phi_{e f f}\left(k_{b f}-k_{p}\right)} k_{b f}+\frac{\rho_{p} \phi_{e f f} c_{p}}{2} \sqrt{\frac{K_{B} T}{3 \pi \mu_{n f} r_{c}}}$

Nabi and Shirani [92] introduced a new theoretical model for thermal conductivity of nanofluids by taking into account of the Brownian motion and resulted micro mixing of nanoparticles and clusters, as well as aggregation kinetics of nanoparticles and clusters. The proposed model was expressed as a combination of static and dynamic parts diffusive as

$k_{\text {eff }}=k_{\text {static }}+k_{\text {dynamic }}$

where Maxwell's was used for the static part $k_{\text {static }}$ and $k_{\text {dynamic }}$ was evaluated as

$k_{\text {dynamic }}=9064\left(\rho c_{v}\right) \times \frac{k_{b f} T}{\mu r_{p}}\left[\beta_{p}\left(\phi-\phi^{\frac{d_{l}-d_{f}}{d_{f}-3}}\right)+\beta_{a} \phi^{\frac{d_{l}-d_{f}}{d_{f}-3}}\left(1+\frac{t}{t_{b r}}\right)^{-\frac{1}{3}}\right]$ 
where $d_{l}$ is the fractal dimension of backbones and $\beta_{p}$ and $\beta_{a}$ are semi-empirical parameters which represent the fraction of the liquid volume traveling with a particle and cluster, respectively.

Li et al. [93] modified $\mathrm{Li}-\mathrm{Qu}-\mathrm{Feng}$ [91] model in order to calculate thermal conductivity of CNTs nanofluids. They showed that $\mathrm{Li}-\mathrm{Qu}-\mathrm{Feng}$ [91] model underestimates the experiment results and is unable to predict thermal conductivity of CNTs nanofluids while no shape factor was included into the model for the special shape of CNTs. Their model taking into account the effect of liquid layering, particle clustering, particle shape factor, Brownian motion and viscosity of base fluid as

$k_{e f f}=\frac{k_{C N T e}+\left(Q_{e s f}-1\right) k_{b f}+\left(Q_{e s f}-1\right) \phi_{e f f}\left(k_{C N T e}-k_{b f}\right)}{k_{C N T e}+\left(Q_{e s f}-1\right) k_{b f}-\phi_{e f f}\left(k_{C N T e}-k_{b f}\right)} k_{b f}+\frac{\rho \phi_{e f f} c_{p}}{2} \sqrt{\frac{K_{B} T}{3 \pi \mu_{n f} r_{c}}}$

where $k_{C N T e}$ and $\phi_{\text {eff }}$ are effective thermal conductivity of CNTs and effective volume fraction of nanoparticles considering the nanolayer of nanoparticles, respectively. $Q_{e s f}$ is the empirical shape factor which considered $Q_{e s f}=6$ for CNTs. The predicted thermal conductivities of VFBN containing CNTs by the modified $\mathrm{Li}-\mathrm{Qu}-\mathrm{Feng}$ model were compared with the experimental data as well as Maxwell model [94], Hamilton-Crosser model [95], Jang-Choi model [19] and Li-Qu-Feng model [91]. The results showed an excellent agreement with the measured data. The authors mentioned that their proposed model is more suitable for nanofluids with special shaped other than spherical nanoparticles.

Table 1 [27, 91, 93-101] and Table $2[16,19,21,25,28,33-35,38-40,44,54,59,60,64$, $92,102,103]$ summarize the conventional and dynamic models for the thermal conductivity of nanofluids, respectively and show the model equations and key parameters required for determining thermal conductivity and remarks.

\section{COMPARISON OF DIFFERENT MODELS}

There is no certainty about the correctness of data in literature when the data from different researchers with different set-ups were collected. Most of the offered models are compared with different data of different investigations. On the other hand, there is no approved database for the properties of nanoparticles as well. In this regard, the researchers benchmarked the thermal conductivity results of different works [104]. For example, in order to find nanoparticle thermal conductivity of aluminium oxide $\left(\mathrm{Al}_{2} \mathrm{O}_{3}\right)$, the following data can be found in the literature; $46 \mathrm{~W} / \mathrm{mK}$ [105-106], $40 \mathrm{~W} / \mathrm{mK}$ [107-108], $36 \mathrm{~W} / \mathrm{mK}$ [109], and also for copper oxide $(\mathrm{CuO}) ; 76.5 \mathrm{~W} / \mathrm{mK}$ [110], $20 \mathrm{~W} / \mathrm{mK}$ [108], $17.65 \mathrm{~W} / \mathrm{mK}$ [109], for almost the same condition. 
Sharifpur et al. [111] investigated a parametric analysis of effective thermal conductivity models for nanofluids. They studied the effect of volume fraction, nanoparticle size and temperature on different models. However, their work attempted to compare the models which do not have adjusting variables. As a result, they found that when the volume fraction of the nanoparticles is less than $1 \%$, most of the models can predict thermal conductivity of nanofluids, but if the volume fraction increases, different models offer different value for the same condition. They also indicated that most of the models which involve the particle size can almost give the same value when the particle size is about $20 \mathrm{~nm}$, but different models give different value for the same condition whenever the particle size is not near $20 \mathrm{~nm}$. Finally, they showed that the models predict different value for thermal conductivity of nanofluids with variation of temperature, when all other parameters are the same.

Regarding the available experimental data of Ho et al. [112] and Das et al. [113] for the thermal conductivity of aluminium oxide nanofluid with an average nanoparticle size of about $30 \mathrm{~nm}$ and at about $\mathrm{T}=300 \mathrm{~K}$ in a water base, Fig. 2 for different models is produced. Figure 2 is an attempt to compare the models which do not have adjusting variables. In using the models, it is assumed that the nanoparticle size is $30 \mathrm{~nm}$, all properties are at $\mathrm{T}=300 \mathrm{~K}$, the thermal conductivity of aluminium oxide $\left(\mathrm{Al}_{2} \mathrm{O}_{3}\right)$ nanoparticles to be $40 \mathrm{Wm}^{-1} \mathrm{~K}^{-1}$, and the thermal conductivity of the water base fluid to be $0.613 \mathrm{Wm}^{-1} \mathrm{~K}^{-1}$. In Fig. 3, the same conditions of Fig. 2 are applied but for copper oxide $(\mathrm{CuO})$. However, it is assumed that the thermal conductivity of copper oxide $(\mathrm{CuO})$ is $20 \mathrm{Wm}^{-1} \mathrm{~K}^{-1}$. The available experimental data of $\mathrm{CuO} /$ water at about $300 \mathrm{~K}$ are the data of Jwo et al. [114] and Mintsa et al. [115].

As shown in Figures 2 and 3, the Maxwell model has almost the same deviation from the experimental data in some parts (in comparison with the recent models). However, the experiments are not matched either. Therefore, there is still a need to work on experimental data and mathematical models. Because of the uncertainty of nanoparticle thermal conductivity and nanolayer thickness, no more graphs are provided in this work.

\section{CONCLUSIONS}

There is an urgent need to understand the fundamental mechanism behind the heat transport in nanofluids under stationary conditions before it is being used in industrial applications. In this paper, different factors that could be potentially responsible for or influence heat transfer enhancement in nanofluids are reviewed. Some theories based on these factors in the open literature are also mentioned.

It was simply found that existing classical models cannot explain the observed enhanced thermal conductivity of nanofluids. The different factors that may influence the thermal conductivity of nanofluids are molecular-level layering of the liquid at the liquid/particle interface (nanolayer), Brownian motion of the nanoparticle, clustering, nanoparticle size, $\mathrm{pH}$, temperature and the nature of heat transport in the nanoparticles. It seems that none of these 
factors could be merely responsible for the enhancement in thermal conductivity; the hybrid model should cover all of these parameters.

However, most of the recently developed models include postulated mechanisms and other effects on nanofluid heat transfer. It is not clear yet which of them is the best model to use for the thermal conductivity of nanofluids, and it requires further investigation. Furthermore, experimental data of different studies do not compare well for apparently the same conditions, which makes it difficult for the model developers. More research is also required on the nature of heat transport in the nanoparticles. To understand the exact mechanisms of heat transfer in nanofluids, further theoretical and experimental investigations are required. Finally, researchers need to have a reliable database for the properties of nanoparticles and experimental data. 


\section{NOMENCLATURE}

\begin{tabular}{|c|c|}
\hline$A_{\text {eсо }}$ & empirical constant \\
\hline$A_{c o}$ & constant \\
\hline$A_{\text {cell }}$ & cross-sectional area of the cubical volume of cell, $\mathrm{m}^{2}$ \\
\hline$B$ & constant for the Kapitza resistance per unit area \\
\hline$B_{c o}$ & constant \\
\hline$B i$ & Biot number \\
\hline$b$ & dipole factor \\
\hline$C_{c o}$ & constant \\
\hline$C_{f t}$ & fitting parameter \\
\hline$C_{p c o}$ & proportional constant \\
\hline$c_{b f}$ & specific heat of liquid phase (base fluid), $\mathrm{J} / \mathrm{kg} \cdot \mathrm{K}$ \\
\hline$c_{p}$ & specific heat capacity of nanoparticle, $\mathrm{J} / \mathrm{kg} \cdot \mathrm{K}$ \\
\hline$c_{f}$ & heat capacity per unit volume of the fluid, $\mathrm{J} / \mathrm{m}^{3} . \mathrm{K}$ \\
\hline$c_{c p}$ & specific heat capacity of complex particle, $\mathrm{J} / \mathrm{kg} \cdot \mathrm{K}$ \\
\hline$c_{v}$ & specific heat, $\mathrm{J} / \mathrm{K}$ \\
\hline$D_{e s f}$ & empirical shape factor \\
\hline$D_{f}$ & fractal dimension \\
\hline$D_{0}$ & nanoparticle diffusion coefficient, $\mathrm{m}^{2} / \mathrm{s}$ \\
\hline$d_{\min }$ & minimum diameter of nanoparticles, $\mathrm{m}$ \\
\hline$d_{\max }$ & maximum diameter of nanoparticles, $\mathrm{m}$ \\
\hline$d_{b f}$ & molecular diameter of base fluid, $\mathrm{m}$ \\
\hline $\bar{d}_{p}$ & average diameter of nanoparticles, $\mathrm{m}$ \\
\hline$d_{p}$ & nanoparticle diameter, $\mathrm{m}$ \\
\hline$d(j, v)$ & depolarization factor \\
\hline$d_{l}$ & fractal dimension of backbones \\
\hline$d_{f}$ & fractal dimension \\
\hline$d_{0}$ & diameter of the outermost layer, $m$ \\
\hline$E_{e s f}$ & empirical shape factor \\
\hline$e$ & elementary charge (electric charge carried by a proton), $\mathrm{C}$ \\
\hline$G_{T}$ & total interparticle potential \\
\hline$H_{c o}$ & constant \\
\hline$h$ & heat transfer coefficient, $\mathrm{W} / \mathrm{m}^{2} . \mathrm{K}$ \\
\hline$i$ & number of time steps used in the simulation \\
\hline
\end{tabular}




\begin{tabular}{|c|c|}
\hline$J$ & net energy flux, $\mathrm{J} / \mathrm{m}^{2}$ \\
\hline$k_{b f}$ & thermal conductivity of base fluid, $\mathrm{W} / \mathrm{m} . \mathrm{K}$ \\
\hline$k_{\text {eff }}$ & effective thermal conductivity, W/m.K \\
\hline$k_{p}$ & thermal conductivity of nanoparticle, $\mathrm{W} / \mathrm{m} . \mathrm{K}$ \\
\hline$k_{m}$ & matrix conductivity, $\mathrm{W} / \mathrm{m} . \mathrm{K}$ \\
\hline$k_{p_{e f f}}$ & effective thermal conductivity of the nanoparticle ,W/m.K \\
\hline$k_{n f}$ & thermal conductivity of nanofluid, W/m.K \\
\hline$k_{E D L}$ & thermal conductivity due to the electrical double layer, $\mathrm{W} / \mathrm{m} . \mathrm{K}$ \\
\hline$k_{\text {eff }-n f}$ & effective thermal conductivity of nanofluid, $\mathrm{W} / \mathrm{m} . \mathrm{K}$ \\
\hline$k_{c p}$ & thermal conductivity of complex particle, $\mathrm{W} / \mathrm{m} . \mathrm{K}$ \\
\hline$k_{p e}$ & equivalent thermal conductivity based on effective theory medium, W/m.K \\
\hline$k_{p n}$ & effective thermal conductivity of nanoparticles, $\mathrm{W} / \mathrm{m} . \mathrm{K}$ \\
\hline$k_{n l}$ & nanolayer (interfacial layer) thermal conductivity,W/m.K \\
\hline$k_{\text {diff }}$ & thermal conductivity due to diffusive heat conduction, W/m.K \\
\hline$k_{\text {Brownian }}$ & thermal conductivity due to particle Brownian motion, $\mathrm{W} / \mathrm{m} . \mathrm{K}$ \\
\hline$k_{\text {excess }}$ & thermal conductivity enhancement due to Brownian motion, $\mathrm{W} / \mathrm{m} . \mathrm{K}$ \\
\hline$k_{\text {Maxwell }}$ & thermal conductivity based on Maxwell conductivity model,W/m.K \\
\hline$k_{p j}$ & equivalent thermal conductivities along the axes of the complex ellipsoid in \\
\hline & which $j(=a, b$ and $c)$ is along the semiaxis directions of the ellipsoid, $\mathrm{W} / \mathrm{m} . \mathrm{K}$ \\
\hline$k_{s l}$ & thermal conductivity of the solid ellipsoid's surrounding layer,W/m.K \\
\hline$k_{s e}$ & thermal conductivity of the solid ellipsoid,W/m.K \\
\hline $\bar{k}$ & equivalent thermal conductivity, W/m.K \\
\hline$k_{C N T}$ & thermal conductivity of carbon nanotubes, W/m.K \\
\hline$k_{C N T e}$ & effective thermal conductivity of carbon nanotubes, $\mathrm{W} / \mathrm{m} . \mathrm{K}$ \\
\hline$K_{B}$ & Boltzmann's constant, $\mathrm{J} / \mathrm{K}$ \\
\hline$l_{b f}$ & liquid mean free path, $\mathrm{m}$ \\
\hline$l_{B}$ & Bjerrum length, $\mathrm{m}$ \\
\hline$l_{P}$ & mean free path of nanoparticle, $\mathrm{m}$ \\
\hline$l_{t}$ & thickness of the liquid layer, $m$ \\
\hline$L_{\text {cell }}$ & length scale of liquid volume, $\mathrm{m}$ \\
\hline$L_{C N T}$ & length of carbon nanotubes, m \\
\hline$M_{e c o}$ & empirical constant \\
\hline$m_{m w}$ & molecular weight of the liquid on the solid interface, $\mathrm{kg}$ \\
\hline$m_{p}$ & mass of the nanoparticle, $\mathrm{kg}$ \\
\hline
\end{tabular}




\begin{tabular}{|c|c|}
\hline$m$ & power law exponent \\
\hline$N_{A}$ & Avogadro's constant, $\mathrm{mol}^{-1}$ \\
\hline $\mathrm{Nu}$ & Nusselt number \\
\hline$n$ & number density of nanoparticles \\
\hline$n_{v}$ & number of complicated particles per volume \\
\hline$N$ & particle concentration, $\mathrm{m}^{-3}$ \\
\hline$N_{p-c}$ & number of parallel carbon nanotubes chain \\
\hline$n_{c-n}$ & number of carbon nanotubes in a chain \\
\hline$O_{c o}$ & constant \\
\hline $\operatorname{Pr}$ & Prandtl number \\
\hline$P_{c o}$ & constant \\
\hline$P_{\text {sde }}$ & system dependent exponent \\
\hline$P_{0}$ & dipole moment of sphere, C.m \\
\hline$P_{L}$ & dipole moment of spheres for longitudinal field, C.m \\
\hline$P_{T}$ & dipole moment of spheres for transverse field, C.m \\
\hline$q$ & electric charge, $\mathrm{C}$ \\
\hline$\langle Q(0) Q(j \Delta t)\rangle$ & time-autocorrelation function of $Q(t)$ \\
\hline$Q_{\text {esf }}$ & empirical shape factor \\
\hline$r_{c}$ & cluster radios, $\mathrm{m}$ \\
\hline$r_{p}$ & radios of nanoparticle, $\mathrm{m}$ \\
\hline$r_{b f}$ & radios of the base fluid molecule, $\mathrm{m}$ \\
\hline $\operatorname{Re}$ & Reynolds number \\
\hline$r$ & spherical coordinate radius, $\mathrm{m}$ \\
\hline$R$ & radius of the outer interface, $\mathrm{m}$ \\
\hline$R_{b}$ & thermal boundary resistance, $\mathrm{m}^{2} . \mathrm{K} / \mathrm{W}$ \\
\hline$R_{n e t}$ & net thermal resistance of the entire nanofluid, $\mathrm{m}^{2} . \mathrm{K} / \mathrm{W}$ \\
\hline$R_{F i, p}$ & thermal resistance in the parallel liquid path, $\mathrm{m}^{2} . \mathrm{K} / \mathrm{W}$ \\
\hline$R_{t r}$ & thermal resistance per unit area of the particle/fluid interface, $\mathrm{m}^{2} . \mathrm{K} / \mathrm{W}$ \\
\hline$R_{C}$ & contact resistance, $\mathrm{m}^{2} . \mathrm{K} / \mathrm{W}$ \\
\hline$t$ & time, $\mathrm{s}$ \\
\hline$t_{b r}$ & characteristic time of Brownian motion, $\mathrm{s}$ \\
\hline$T$ & temperature, ${ }^{\circ} \mathrm{C}$ or $\mathrm{K}$ \\
\hline$T_{n l}$ & temperature inside the nanolayer, ${ }^{\circ} \mathrm{C}$ or $\mathrm{K}$ \\
\hline$T_{f r}$ & freezing-point of the base liquid, ${ }^{\circ} \mathrm{C}$ or $\mathrm{K}$ \\
\hline$V$ & volume of the domain, $\mathrm{m} / \mathrm{s}$ \\
\hline$V_{r}$ & volumetric ratio \\
\hline
\end{tabular}



$\bar{u}_{p}$
average particle velocity, $\mathrm{m} / \mathrm{s}$
$u_{p}$
Brownian velocity of the nanoparticle, $\mathrm{m} / \mathrm{s}$
$X, Y$
parameters determined from the continuity of thermal conductivity at the interface

\section{Greek Symbols}

\begin{tabular}{|c|c|}
\hline$\alpha$ & thermal diffusivity, $\mathrm{m}^{2} / \mathrm{s}$ \\
\hline$\beta_{a}$ and $\beta_{p}$ & semi-empirical parameters \\
\hline$\beta$ & $\begin{array}{l}\text { parameter that represents the hydrodynamic interaction between particles and } \\
\text { affected fluid }\end{array}$ \\
\hline$\gamma$ & ratio of the particle radius to the equivalent matrix thickness \\
\hline$\Gamma$ & Coulomb constant, N.m²/C \\
\hline$\kappa_{D}^{-1}$ & Debye length, $\mathrm{m}^{-1}$ \\
\hline$\delta_{T}$ & thermal boundary layer thickness, $\mathrm{m}$ \\
\hline$\delta_{n l}$ & nanolayer (interfacial layer) thickness, $\mathrm{m}$ \\
\hline$\Delta t$ & time step \\
\hline$\varepsilon$ & permittivity of the liquid, $\mathrm{F} / \mathrm{m}$ \\
\hline$\varepsilon_{b f}$ & dielectric constant of medium \\
\hline$\mu$ & dynamic viscosity, Pa.s \\
\hline$\mu_{b f}$ & dynamic viscosity of the base fluid, Pa.s \\
\hline$\mu_{n f}$ & dynamic viscosity of nanofluid, Pa.s \\
\hline$v$ & kinematic viscosity, $\mathrm{m}^{2} / \mathrm{s}$ \\
\hline$v_{p}$ & kinematic viscosity of nanoparticle, $\mathrm{m}^{2} / \mathrm{s}$ \\
\hline$\rho_{p}$ & density of nanoparticle, $\mathrm{kg} / \mathrm{m}^{3}$ \\
\hline$\rho_{n f}$ & density of nanofluid, $\mathrm{kg} / \mathrm{m}^{3}$ \\
\hline$\rho_{b f}$ & density of liquid phase (base fluid), $\mathrm{kg} / \mathrm{m}^{3}$ \\
\hline$\rho_{c p}$ & density of complex particle, $\mathrm{kg} / \mathrm{m}^{3}$ \\
\hline$\rho_{i}$ & number density of ionic charge in the bulk liquid, $\mathrm{kg} / \mathrm{m}^{3}$ \\
\hline$\varsigma$ & Kapitza resistance, $\mathrm{K}^{4} \cdot \mathrm{m}^{2} / \mathrm{W}$ \\
\hline$\tau$ & particle relaxation time, $\mathrm{s}$ \\
\hline$\phi$ & volume fraction \\
\hline$\phi_{p}$ & volume fraction of nanoparticle \\
\hline$\phi_{p l}$ & volume fraction of nanoparticle plus the nanolayer \\
\hline$\Phi$ & volume of the particle, $\mathrm{m}^{3}$ \\
\hline$\phi_{e f f}$ & effective volume fraction \\
\hline$\phi_{e}$ & equivalent volume concentration of complex ellipsoids \\
\hline
\end{tabular}




$\begin{array}{ll}\phi_{n l} & \text { nanolayer (interfacial layer) volumetric fraction } \\ \phi_{t} & \text { total volume fraction } \\ \phi_{0} & \text { original volume fraction of nanoparticles } \\ \psi & \text { empirical parameter } \\ \Psi & \text { sphericity } \\ \Omega & \text { Kapitza length and the particle radius ratio } \\ \omega & \text { empirical constant }\end{array}$

\section{REFERENCES}

[1] Trisaksri, V. and Wongwises, S., Critical review of heat transfer characteristics of nanofluids, Journal of Renewable and Sustainable Energy, Vol. 11, pp. 512-523, 2007.

[2] Akbari, M., Behzadmehr, F. and Shahraki, F., Fully developed mixed convection in horizontal and inclined tubes with uniform heat flux using nanofluid, International Journal of Heat and Fluid Flow, Vol. 29, pp. 545 - 556, 2008.

[3] Xuan, Y. and Li Q., Heat transfer enhancement of nanofluids, International Journal of Heat and Fluid Flow, Vol. 21, pp. 58-64, 2000.

[4] Choi, S.U.S., Enhancing thermal conductivity of fluids with nanoparticles. In: Siginer, ASME, New York, FED -Vol. 231/MD, Vol. 66, pp. 99-105, 1995.

[5] Li, Y., Zhou, J., Tung, S., Schneider, E. and Xi, S., A review on development of nanofluid preparation and characterization, Powder Technology, Vol. 196, pp. 89-101, 2009.

[6] Kakaç, S. and Pramuanjaroenkij, A., Review of convective heat transfer enhancement with nanofluids, International Journal of Heat and Mass Transfer, Vol. 52, pp. 31873196, 2009.

[7] Wen, D., Lin, G. and Zhang, K., Review of nanofluids for heat transfer applications, Particuology, Vol. 7, pp. 141-150, 2009.

[8] Chandrasekar, M. and Suresh, S., A Review on the Mechanisms of Heat Transport in Nanofluids, Heat Transfer Engineering, Vol. 30: 14 pp. 1136-1150, 2009.

[9] Godson, L., Raja, B., Mohan, L. D. and Wongwises S., Enhancement of heat transfer using nanofluids - An overview, Renewable and Sustainable Energy Reviews, Vol. 14, pp. 629-641, 2010.

[10] Saidur, R., Leong, K.Y. and Mohammad, H.A., A review on applications and challenges of nanofluids, Renewable and Sustainable Energy Reviews, Vol. 15, pp. 1646-1668, 2011. 
[11] Das, S. K., Choi, S.U.S., Yu, W. and Pradeep T., Nanofluid science and technology, John Wiley \& Sons Inc., Hoboken, New Jersey, 2007.

[12] Wang, X.Q., Mujumdar, A.S., Heat transfer characteristics of nanofluids: review, International Journal of Thermal Science, Vol. 46, pp. 1-19, 2007.

[13] Keblinski, P., Phillpot, S.R., Choi, S.U.S. and Eastman, J.A., Mechanisms of heat flow in suspensions of nano-sized particles (nanofluids), International Journal of Heat and Mass Transfer, Vol. 45, pp. 855-863, 2002.

[14] Wang, J.J., Zheng, R.T., Gao, J.W., Chen, G., Heat conduction mechanisms in nanofluids and Suspensions, Nano Today, Vol.7, pp. 124-136, 2012.

[15] Evans, W., Fish, J. and Keblinski, P., Role of Brownian motion hydrodynamics on nanofluids thermal conductivity, Applied Physics Letters, Vol. 88, pp. 93-116, 2006.

[16] Xuan, Y., Li, Q. and $\mathrm{Hu}$ W., Aggregation structure and thermal conductivity of nanofluids, Journal of American Institute of Chemical Engineers (AIChE), Vol. 49(4), pp. 1038-1043, 2003.

[17] Das, S. K., Putra, N., Thiesen, P., and Roetzel, W., Temperature Dependence of Thermal Conductivity Enhancement for Nanofluids, Journal of Heat Transfer, Transactions of the ASME, Vol. 125, no. 4, pp. 567-574, 2003.

[18] Yu, W., Hull, J.H. and Choi S.U.S., Stable and highly conductive nanofluids: experimental and theoretical studies, TED-AJ03-384, Proceedings of the 6th ASMEJSME Thermal Engineering Joint Conference (AJTEC2003), March 16-20, 2003, Kohala Coast, Hawaii Island, Hawaii, USA.

[19] Jang, S.P. and Choi, S.U.S., Role of Brownian motion in the enhanced thermal conductivity of nanofluids, Applied Physics Letters, Vol. 84, pp. 4316-4318, 2004.

[20] Bhattacharya, P., Saha, S.K., Yadav, A. and Phelan P.E., Brownian dynamics simulation to determine the effective thermal conductivity of nanofluids, Journal of Applied Physics, Vol. 95, no. 11, pp. 6492-6494, 2004.

[21] Kumar, D. H., Patel, H. E., Kumar, V. R. R., Sundararajan, T., Pradeep, T., and Das, S. K., Model for heat conduction in nanofluids, Physical Review Letters, vol. 93, no. 14, pp. 144301-1-144301-4, 2004.

[22] Bastea, S., Comment on "Model for heat conduction in nanofluids", Physics Review Letters, Vol. 95, IS 1, AR 019491, 2005.

[23] Das, S.K., Sundararajan, T., Pradeep, T., and Patel, H.E., Comment on "Model for heat conduction in nanofluids" - Reply, Phycics Review Letters, Vol. 95, IS 20, AR 209402, 2005 . 
[24] Keblinski, P. and Cahill, D.G., Comment on Model for heat conduction in nanofluids, Phycics Review Letters, Vol. 95, IS 20, AR 209401, 2005.

[25] Koo, J. and Kleinstreuer, C., A new thermal conductivity model for nanofluids, Journal of Nanoparticle Research, vol. 6, no. 6, pp. 577-588, 2004.

[26] Koo, J., and Kleinstreuer, C., Impact Analysis of Nanoparticle Motion Mechanisms on the Thermal Conductivity of Nanofluids, International Communications in Heat and Mass Transfer, vol. 32, pp. 1111-1118, 2005.

[27] Wasp, F.J., Solid-Liquid Flow Slurry Pipeline Transportation .Trans. Tech. Pub., Berlin, 1977.

[28] Prasher, R., Bhattacharya, P., and Phelan, P. E., Thermal conductivity of nanoscale colloidal solutions (nanofluids), Physical Review Letters, vol. 94, no. 2, pp. 025901-1025901-4, 2005.

[29] Das, S. K., Sundararajan, T., Pradeep, T., and Patel, H. E., Reply, Physical Review Letters, vol. 95, p. 019402, 2005.

[30] Chon, C. H., Kihm, K. D., Lee, S. P. and Choi, S.U.S., Empirical correlation finding the role of temperature and particle size for nanofluid $\left(\mathrm{Al}_{2} \mathrm{O}_{3}\right)$ thermal conductivity enhancement, Applied Physics Letter, vol. 87, no.15, pp. 153107-1-153107-3, 2005.

[31] Ren, Y., Xie, H., Cai, A., Effective thermal conductivity of nanofluids containing spherical nanoparticles, Journal of Physics D: Applied Physics, Vol. 38, pp. 3958-3961, 2005 .

[32] Patel, H.E., Sundararajan, T., Pradeep, T., Dasgupta, A., Dasgupta, N. and Das, S.K., A micro-convection model for thermal conductivity of nanofluids, Pramana - Journal of Physics, Vol. 65, pp. 863-869, 2005.

[33] Bhattacharya, P., Phelan, P.E. and Prasher, R., Brownian-motion-based convectiveconductive model for the effective thermal conductivity of nanofluids, Journal of Heat Transfer, Vol. 128, pp. 588-595, 2006.

[34] Xu, J., Yu, B., Zou, M. and Xu, P., A new model for heat conduction of nanofluids based on fractal distributions of nanoparticles, Journal of Applied Physics, Vol. 39, pp. 4486-4490, 2006.

[35] Vladkov, M. and Barrat, J.L., Modeling transient absorption and thermal conductivity in a simple nanofluid, Nano Letters, vol. 6, no. 6, pp. 1224-1228, 2006.

[36] Li, C. H. and Peterson, G. P., Mixing effect on the enhancement of the effective thermal conductivity of nanoparticle suspensions (nanofluids), International Journal of Heat and Mass Transfer, vol. 50, no. 23-24, pp. 4668-4677, 2007. 
[37] Sarkar, S. and Selvam, R. P., Molecular dynamics simulation of effective thermal conductivity and study of enhanced thermal transport mechanism in nanofluids, Journal of Applied Physics, vol. 102, no. 7, pp. 074302-1-074302-7, 2007.

[38] Yu-Hua, L., Wei, Q. and Jian-Chao, F., Temperature dependence of thermal conductivity of nanofluids, Chinese Physics Letters, Vol. 25, No.9, p. 3319, 2008.

[39] Shukla, R. K. and Dhir, V. K., Effect of Brownian motion on thermal conductivity of nanofluids, Journal of Heat Transfer, vol. 130, no. 4, pp. 042406-1-042406-13, 2008.

[40] Yang, B., Thermal conductivity equations based on Brownian motion in suspensions of nanoparticles (nanofluids), Journal of Heat Transfer, vol. 130, no. 4, pp. 042408-1042408-5, 2008.

[41] Nie, C., Marlow, W.H. and Hassan, Y.A., Discussion of proposed mechanisms of thermal conductivity enhancement in nanofluids, International Journal of Heat and Mass Transfer, Vol. 51, pp. 1342-1348, 2008.

[42] Vasu, V., Krishna, K. R., and Kumar, A. C. S., "Analytical prediction of thermophysical properties of fluids embedded with nanostructured materials," International Journal of Nanoparticles, vol. 1, no. 1, pp. 32-49, 2008.

[43] Jain, S., Patel, H. E., and Das, S. K., "Brownian dynamics simulation for the prediction of effective thermal conductivity of nanofluid," Journal of Nanoparticle Research, vol. 11, no. 4, pp. 767-773, 2009.

[44] Jung, J.Y., Yoo, J.Y., Thermal conductivity enhancement of nanofluids in conjunction with electrical double layer (EDL), International Journal of Heat and Mass Transfer, Vol.52, pp. 525-528, 2009.

[45] Murshed, S.M.S., Leong, K.C., Yang, C., A combined model for the effective thermal conductivity of nanofluids, Applied Thermal Engineering, Vol. 29, pp. 2477-2483, 2009.

[46] Emami-Meibodi, M., Vafaie-Sefti, M., Rashidi, A.M., Amrollahi, A., Tabasi, M. and Sid-Kalal, H., A model for thermal conductivity of nanofluids, Materials Chemistry and Physics, Vol. 123, pp. 639-643, 2010.

[47] Meibodi, M.E., Vafaie-Sefti, M., Rashidi, A.M., Amrollahi, A., Tabasi, M. and Kalal, H.S., Simple model for thermal conductivity of nanofluids using resistance model approach, International Communications in Heat and Mass Transfer, Vol. 37, pp. 555559, 2010.

[48] Teng, T., Hung, Y., Teng, T., Mo, H. and Hsu, H., The effect of alumina/water nanofluid particle size on thermal conductivity, Applied Thermal Engineering, Vol. 30, pp. 2213$2218,2010$. 
[49] Mehta, S., Chauhan, K. P. and Kanagaraj, S., Modeling of thermal conductivity of nanofluids by modifying Maxwell's equation using cell model approach, Journal of Nanoparticle Research, Vol. 13, pp.2791-2798, 2011.

[50] Xiao, B., Yang, Y. and Chen, L., Developing a novel form of thermal conductivity of nanofluids with Brownian motion effect by means of fractal geometry, Powder Technology, Vol. 239, pp. 409-414, 2013.

[51] Babaei, H., Keblinski, P. and Khodadadi, J. M., A proof for insignificant effect of Brownian motion-induced microconvection on thermal conductivity of nanofluids by utilizing molecular dynamics simulations, Journal of Applied Physics, Vol.113, pp. 084302, 2013.

[52] Henderson, J.R. and Swol, F.V., On the interface between a fluid and a planar wall: Theory and simulations of a hard sphere fluid at a hard wall, Molecular Physics, Vol. 51, pp. 991-1010, 1984.

[53] Yu, C.J., Richter, A.G., Datta, A., Durbin, M.K. and Dutta, P., Molecular layering in a liquid on a solid substrate: An X-ray reflectivity study, Physica B, Vol. 283, pp. 27-31, 2000 .

[54] $\mathrm{Yu}$, W. and Choi, S.U.S., The role of interfacial layers in the enhanced thermal conductivity of nanofluids: A renovated Maxwell model, Journal of Nanoparticle Research, Vol. 5, pp. 167-171, 2003.

[55] Feng, Y., Yu, B., and Zou, M., The effective thermal conductivity of nanofluids based on the nanolayer and the aggregation of nanoparticles, Journal of Physics D: Applied Physics, Vol. 40, pp. 3164-3171, 2007.

[56] $\mathrm{Yu}, \mathrm{W}$. and Choi, S.U.S., The role of interfacial layers in the enhanced thermal conductivity of nanofluids: A renovated Hamilton-Crosser model, Journal of Nanoparticle Research, Vol. 6, pp. 355-361, 2004.

[57] Xue, L., Keblinski, P., Phillpot, S.R., Choi, S.U.S. and Eastman, J.A., Two regimes of thermal resistance at a liquid-solid interface, Journal of Chemical Physics, Vol. 118:1, 2003.

[58] Xue, Q.Z., Model for effective thermal conductivity of nanofluids, Physics Letters A, Vol. 307, pp. 313-317, 2003.

[59] Xie, H., Fujii, M. and Zhang X., Effect of interfacial nanolayer on the effective thermal conductivity of nanoparticle-fluid mixture, International Journal of Heat and Mass Transfer, Vol. 48, pp. 2926-2932, 2005.

[60] Leong, K.C., Yang, C. and Murshed S.M.S., A model for the thermal conductivity of nanofluids - the effect of interfacial layer, Journal of Nanoparticle Research, Vol. 8, pp. 245-254, 2006. 
[61] Tillman, P. and Hill, J.M., Determination of nanolayer thickness for a nanofluid, International Communications in Heat and Mass Transfer, Vol. 34, pp. 399-407, 2007.

[62] Li, L., Zhang, Y., Ma, H., and Yang, M., An investigation of molecular layering at the liquid-solid interface in nanofluids by molecular dynamics simulation, Physics Letters A, Vol. 372, pp. 4541-4544, 2008.

[63] Zhou, X.F. and Gao, L., Thermal conductivity of nanofluids: Effects of graded nanolayers and mutual interaction, Journal of Applied Physics, Vol.103, pp. 083503, 2008.

[64] Lin, Y.S., Hsiao, P.Y. and Chieng, C.C., Roles of nanolayer and particle size on thermophysical characteristics of ethylene glycol-based copper nanofluids, Applied Physics Letters, Vol. 98, pp.153105, 2011.

[65] Hwang, Y., Lee, J.K., Jeong, Y.M., Cheong, S.I., Ahn, Y.C. and Kim, S.H., Production and dispersion stability of nanoparticles in nanofluids, Journal of Powder Technology, Vol. 186, pp. 145-153, 2008.

[66] Karthikeyan, N.R., Philip, J. and Raj, B., Effect of clustering on the thermal conductivity of nanofluids, Materials Chemistry and Physics, Vol. 109, pp. 50-55, 2008.

[67] Hong, K.S., Hong, T.K. and Yang, H.S., Thermal conductivity of Fe nanofluids depending on the cluster size of nanoparticles, Applied Physics Letters, Vol. 88, p. 031901, 2006.

[68] Wang, B.X., Zhou, L.P. and Peng, X.F., A fractal model for predicting the effective thermal conductivity of liquid with suspension of nanoparticles, International Journal of Heat and Mass Transfer, Vol. 46, pp. 2665-2672, 2003.

[69] Murshed, S.M.S., Leong, K.C. and Yang, C., Thermophysical and electrokinetic properties of nanofluids - A critical review, Applied Thermal Engineering, Vol. 28, pp. 2109-2125, 2008.

[70] Prasher, R., Phelan, P.E. and Bhattacharya, P., Effect of aggregation kinetics on the thermal conductivity of nanoscale colloidal solution (nanofluids), Nano Letters, Vol. 6, pp. 1529-1534, 2006.

[71] Prasher, R., Evans, W., Meakin, P., Phelan, J. P. and Keblinski, P., Effect of aggregation on thermal conduction in colloidal nanofluids, Applied Physics Letters, Vol. 89, p. 143119, 2006.

[72] Agop, M., Paun, V. and Harabagiu, A., El Naschie's theory and effects of nanoparticle clustering on the heat transport in nanofluids, Chaos, Solitons and Fractals, Vol. 37, pp. 1269-1278, 2008. 
[73] Okeke, G., Witharana, S., Antony, S. J. and Ding, Y., Computational analysis of factors influencing thermal conductivity of nanofluids, Journal of Nanoparticle Research, Vol.13, pp. 6365-6375, 2011.

[74] Witharana, S., Hodges, C., Xu, D., Lai, X., and Ding, Y., Aggregation and settling in aqueous polydisperse alumina nanoparticle suspensions, Journal of Nanoparticle Research, Vol.14 (5), pp. 0851, 2012.

[75] Viota, J.L., González-Caballero, F., Durán, J.D.G. and Delgado, A.V., Study of the colloidal stability of concentrated bimodal magnetic fluids, Journal of Colloid and Interface Science, Vol. 309, pp. 135-139, 2007.

[76] Yeganeh, M., Shahtahmasebi, N., Kompany, A., Goharshadi, E.K., Youssefi, A. and Šller L., Volume fraction and temperature variations of the effective thermal conductivity of nanodiamond fluids in deionized water, International Journal of Heat and Mass Transfer, Vol. 53, pp. 3186-3192, 2010.

[77] Strandberg, R. and Das, D.K., Influence of temperature and properties variation on nanofluids in building heating, Energy Conversion and Management, Vol. 51, pp. 1381-1390, 2010.

[78] Duangthongsuk, W. and Wongwises, S., Measurement of temperature-dependent thermal conductivity and viscosity of TiO2-water nanofluids, Experimental Thermal and Fluid Science, Vol. 33, pp. 706-714, 2009.

[79] Nguyen C.T., Desgranges F., Roy G., Galanis N., Mare’ T., Boucher S., and Angue Mintsa, H., Temperature and particle-size dependent viscosity data for water-based nanofluids - Hysteresis phenomenon, International Journal of Heat and Fluid Flow, Vol. 28, pp. 1492-1506, 2007.

[80] Wanga, X., Zhu, D., and Yang, S., Investigation of $\mathrm{pH}$ and SDBS on enhancement of thermal conductivity in nanofluids, Chemical Physics Letters, Vol. 470, pp. 107-111, 2009.

[81] Li, X.F., Zhu, D.S., Wang, X.J., Wang, N., Gao, J.W. and Li, H., Thermal conductivity enhancement dependent $\mathrm{pH}$ and chemical surfactant for $\mathrm{Cu}$ - nanofluids, Thermochimica Acta, Vol. 469, pp. 98-103, 2008.

[82] Xie, H., Yu, W., Li, Y. and Chen, L., Discussion on the thermal conductivity enhancement of nanofluids, Nanoscale Research Letters, Vol. 6:124/1, 2011.

[83] Zhu, D., Li, X., Wang, N., Wang, X., Gao, J. and Li, H., Dispersion behavior and thermal conductivity characteristics of - nanofluids, Current Applied Physics, Vol. 9, pp. 131-139, 2009.

[84] Anoop, K.B., Sundararajan, T. and Das, S.K., Effect of particle size on the convective heat transfer in nanofluid in the developing region, International Journal of Heat and Mass Transfer, Vol. 52, pp. 2189-2195, 2009. 
[85] Pastoriza-Gallego, M.J., Casanova, C., Legido, J.L. and Pineiro, M.M., CuO in water nanofluid: Influence of particle size and polydispersity on volumetric behaviour and viscosity, Fluid Phase Equilibria, Vol. 300, pp. 188-196, 2011.

[86] Ji, Y., Ma, H., Su, F. and Wang, G., Particle size effect on heat transfer performance in an oscillating heat pipe, Experimental Thermal and Fluid Science, Vol. 35(4), pp. 724$727,2011$.

[87] Avsec, J., The combined analysis of phonon and electron heat transfer mechanism on thermal conductivity for nanofluids, International Journal of Heat and Mass Transfer, Vol. 51, pp. 4589-4598, 2008.

[88] Prasher, R., Generalized equation for phonon radiative transport, Applied Physics Letters, Vol. 83 (1), pp. 48-50, 2003.

[89] Corcione, M., Empirical correlating equations for predicting the effective thermal conductivity and dynamic viscosity of nanofluids, Energy Conversion and Management, Vol. 52, pp. 789-793, 2011.

[90] Corcione, M., Rayleigh-Bénard convection heat transfer in nanoparticle suspensions, International Journal of Heat and Fluid Flow, Vol. 32, pp. 65-77, 2011.

[91] Li, Y.H., Qu, W. and Feng, J.C., Temperature dependence of thermal conductivity of nanofluids, Chinese Physics Letters, Vol. 25, No.9, pp.3319, 2008.

[92] Nabi, S., Shirani, E., Simultaneous effects of Brownian motion and clustering of nanoparticles on thermal conductivity of nanofluids, Iranian Journal of Science and Technology. Transactions of Mechanical Engineering, Vol. 36, pp. 53-68, 2012.

[93] Li, F.C., Yang, J.C., Zhou, W.W., He, Y.R., Huang, Y.M. and Jiang, B.C., Experimental study on the characteristics of thermal conductivity and shear viscosity of viscoelasticfluid-based nanofluids containing multiwalled carbon nanotubes, Thermochimica Acta, Vol.556, pp. 47- 53, 2013.

[94] Maxwell, J.C., A treatise on electricity and magnetism, Oxford: Clarendon, 1891

[95] Hamilton, R.L., Crosser, O.K., Thermal conductivity of heterogeneous two-component systems. I \& EC Fundamentals, Vol.1, pp. 182-191, 1962.

[96] Jeffrey D.J., Conduction through a random suspension of spheres. Proceedings of Royal Society, Vol. 335 pp.355-367, 1973.

[97] Bruggeman, D.A.G., Berechnung Verschiedener Physikalischer Konstanten von Heterogenen Substanzen, I. Dielektrizitatskonstanten und Leitfahigkeiten der Mischkorper aus Isotropen Substanzen. Annalen der Physik. Leipzig Vol. 24, pp.636679, 1935. 
[98] Lu, S.Y., Lin, H.C., Effective conductivity of composites containing aligned spheroidal inclusions of finite conductivity, Journal of Applied Physics, Vol. 79 (9), pp.6761$6769,1996$.

[99] Davis, R.H., The effective thermal conductivity of a composite material with spherical inclusions, International Journal of Thermophysics, Vol. 7, pp. 609-620, 1986.

[100] Sastry, N.N.V., Bhunia, A., Sundararajan, T. and Das, S.K., Predicting the effective thermal conductivity of carbon nanotube based nanofluids, Nanotechnology, Vol. 19, pp. 055704. 2008.

[101] Syam Sundar, L., Singh, Manoj. K. and Sousa, Antonio .C.M., Investigation of thermal conductivity and viscosity of $\mathrm{Fe}_{3} \mathrm{O}_{4}$ nanofluid for heat transfer applications, International Communications in Heat and Mass Transfer, Vol. 44, pp.7-14, 2013.

[102] Murshed, S.M.S., Leong, K.C. and Yang, C., Investigations of thermal conductivity and viscosity of nanofluids, International Journal of Thermal Sciences, Vol. 47, pp. 560-568, 2008.

[103] Shima, P.D., Philip, J. and Baldev R., Role of microconvection induced by Brownian motion of nanoparticles in the enhanced thermal conductivity of stable nanofluids, Appl. Phys. Lett., Vol. 94, pp. 223101, 2009.

[104] Buongiorno, J., Venerus, D.C., Prabhat, N., McKrell, T., Townsend, J., Christianson, R., Tolmachev, Y.V., Keblinski, P., Hu, L., Alvarado, J.L., Bang, I.C., Bishnoi, S.W., Bonetti, M., Botz, F., Cecere, A., Chang, Y., Chen, G., Chen, H., Chung, S.J., Chyu, M.K., Das, S.K., Paola, R.D., Ding, Y., Dubois, F., Dzido, G., Eapen, J., Escher, W., Funfschilling, D., Galand, Q., Gao, J., Gharagozloo, P.E., Goodson, K.E., Gutierrez, J.G., Hong, H., Horton, M., Hwang, K.S., Iorio, C.S., Jang, S.P., Jarzebski, A.B., Jiang, Y., Jin, L., Kabelac, S., Kamath, A., Kedzierski, M.A., Kieng, L.G., Kim, C., Kim, J., Kim, S., Lee, S.H., Leong, K.C., Manna, I., Michel, B., Ni, R., Patel, H.E., Philip, J., Poulikakos, D., Reynaud, C., Savino, R., Singh, P.K., Song, P., Sundararajan, T., Timofeeva, E., Tritcak, T., Turanov, A.N., Vaerenbergh, S.V., Wen, D., Witharana, S., Yang, C., Yeh, W., Zhao X. and Zhou, S., A benchmark study on the thermal conductivity of nanofluids, Journal of Applied Physics, Vol. 106, p. 094312, 2009.

[105] Saleh, H., Roslan, R. and Hashim, I., Natural convection heat transfer in a nanofluidfilled trapezoidal enclosure, International Journal of Heat and Mass Transfer, Vol. 54, pp. 194-201, 2011.

[106] Ho, C.J., Chen, M.W. and Li, Z.W., Numerical simulation of natural convection of nanofluid in a square enclosure: Effects due to uncertainties of viscosity and thermal conductivity, International Journal of Heat and Mass Transfer, Vol. 51, pp. 45064516, 2008. 
[107] Pakravan, H.A. and Yaghoubi, M., Combined thermophoresis, Brownian motion and Dufour effects on natural convection of nanofluids, International Journal of Thermal Sciences, Vol. 50, pp. 394-402, 2011.

[108] Abu-Nada, E., Masoud, Z. and Hijazi, A., Natural convection heat transfer enhancement in horizontal concentric annuli using nanofluids, International Communications in Heat and Mass Transfer, Vol. 35, pp. 657-665, 2008.

[109] Vajjha, R.S., Das, D.K. and Kulkarni, D.P., Development of new correlations for convective heat transfer and friction factor in turbulent regime for nanofluids, International Journal of Heat and Mass Transfer, Vol. 53, pp. 4607-4618, 2010.

[110] Ghasemi, B. and Aminossadat, S.M., Brownian motion of nanoparticles in a triangular enclosure with natural convection, International Journal of Thermal Sciences, Vol. 49, pp. 931-940, 2010.

[111] Sharifpur, M., Ntumba, T. and Meyer, J.P., Parametric analysis of effective thermal conductivity models for nanofluids, Proceedings of the ASME 2012 International Mechanical Engineering Congress and Exposition, Volume 9: Micro- and NanoSystems Engineering and Packaging, Parts A and B, pp. 1-11, November 9-15, 2012, Houston, Texas, USA.

[112] Ho, C.J., Liu, W.K., Chang, Y.S. and Lin, C.C., Natural convection heat transfer of alumina-water nanofluid in vertical square enclosures: An experimental study, International Journal of Thermal Sciences, Vol. 49, pp. 1345-1353, 2010.

[113] Das, S.K., Putra, N., Thiesen, P. and Roetzel, W., Temperature dependence of thermal conductivity enhancement for nanofluids, Journal of Heat Transfer, Vol. 125, pp. 567574, 2003.

[114] Jwo, C., Chang, H., Teng, T., Kao, M. and Guo, Y., A Study on the effect of temperature and volume fraction on thermal conductivity of copper oxide, Journal of Nanoscience and Nanotechnology, Vol. 7, pp. 2161-2166, 2007.

[115] Mintsa, H.A., Roy, G., Nguyen, C.T. and Doucet, D., New temperature dependent thermal conductivity data for water-based nanofluids, International Journal of Thermal Sciences, Vol. 48, pp. 363-371, 2009. 
Table 1. Summary of the studies on the theoretical models for thermal conductivity of nanofluids - Conventional Models

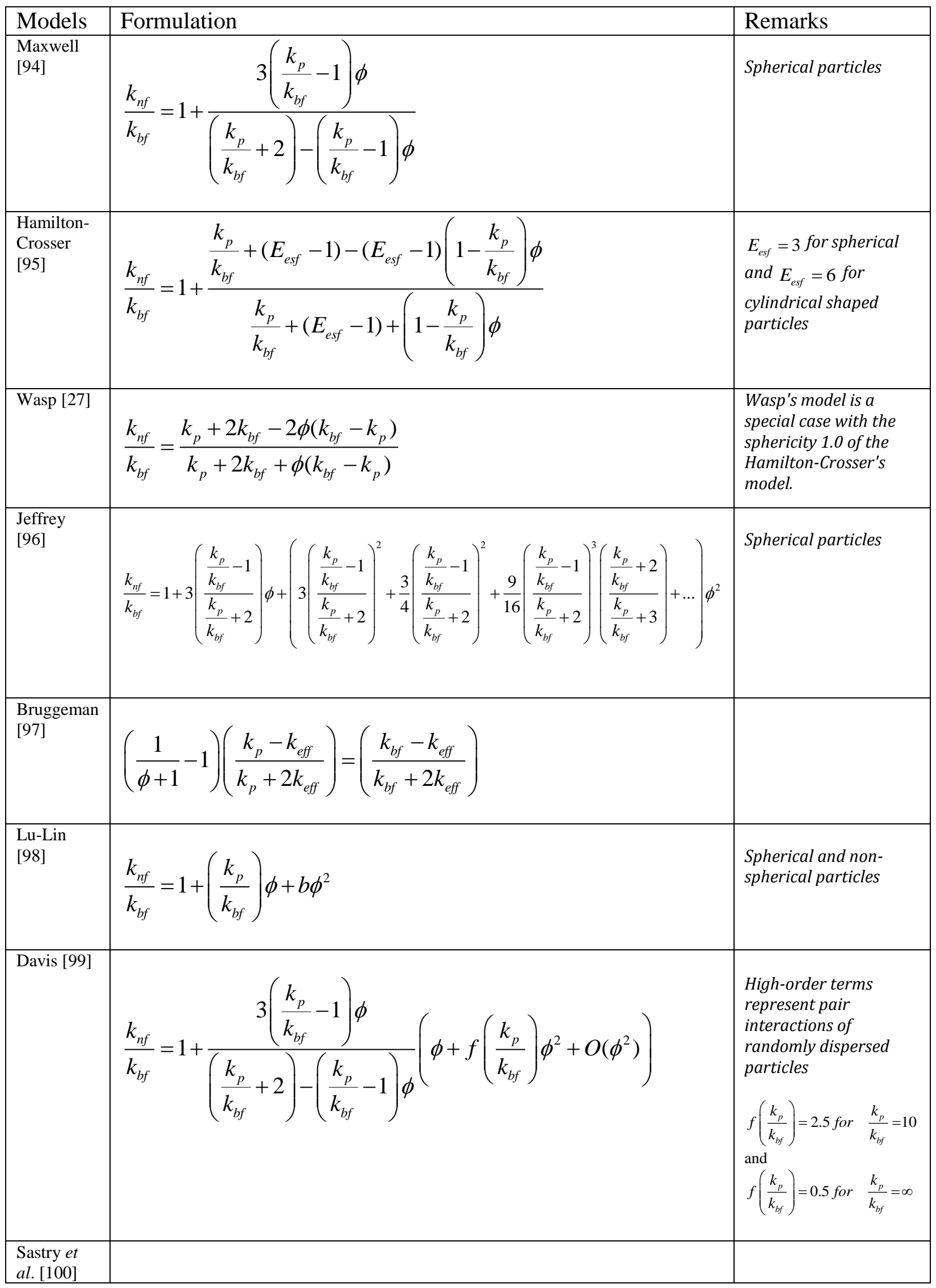




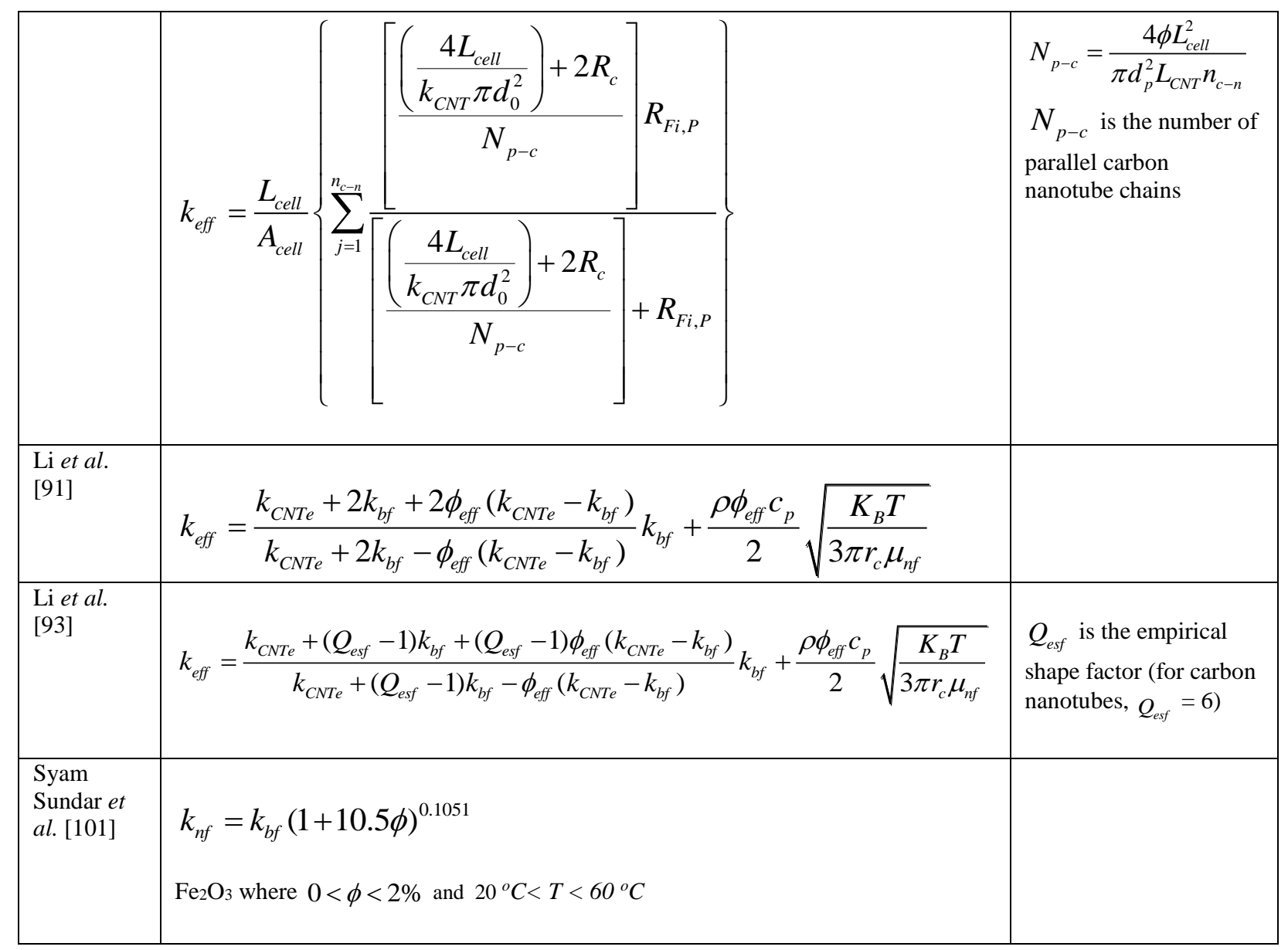


Table 2. Summary of the studies on the theoretical models for thermal conductivity of nanofluids - Dynamic models

\begin{tabular}{|c|c|c|}
\hline Models & Formulation & Remarks \\
\hline $\begin{array}{l}\text { Xuan et al. } \\
{[16]}\end{array}$ & $\frac{k_{e f f}}{k_{b f}}=\frac{k_{p}+2 k_{b f}-2 \phi\left(k_{b f}-k_{p}\right)}{k_{p}+2 k_{b f}+\phi\left(k_{b f}-k_{p}\right)}+\frac{\rho_{p} \phi c_{p}}{2 k_{b f}} \sqrt{\frac{K_{B} T}{3 \pi r_{c} \mu}}$ & \\
\hline $\begin{array}{l}\text { Jang-Choi } \\
{[19]}\end{array}$ & $k_{e f f}=k_{b f}\left(1-\phi_{e f f}\right)+B k_{p} \phi_{e f f}+C_{p c o} \frac{d_{b f}}{d_{p}} k_{b f} \operatorname{Re}_{d_{p}}^{2} \phi_{e f f}$ & $\begin{array}{l}\text { Where } B \text { is a constant for } \\
\text { considering the Kapitza resistance } \\
\text { per unit area and the Reynolds } \\
\text { number is } \operatorname{Re}=\frac{D_{0} d_{p}}{l_{b f} v}\end{array}$ \\
\hline $\begin{array}{l}\text { Kumar } e t \\
\text { al. [21] }\end{array}$ & $\frac{k_{e f f}}{k_{b f}}=1+C_{c o} \bar{u}_{p} \frac{\phi r_{b f}}{k_{b f}(1-\phi) r_{p}}$ & \\
\hline $\begin{array}{l}\text { Koo and } \\
\text { Kleinstreuer } \\
{[25]}\end{array}$ & $k_{e f f}=\left[\frac{k_{p}+2 k_{b f}-2 \phi\left(k_{b f}-k_{p}\right)}{k_{p}+2 k_{b f}+\phi\left(k_{b f}-k_{p}\right)}\right] k_{b f}+\left[5 \times 10^{4} \beta \phi_{p} \rho_{b f} c_{b f} \sqrt{\frac{K_{B} T}{\rho_{p} d_{p}}} f\left(T, \phi_{p}, e t c.\right)\right]$ & $\begin{array}{l}\text { For } \mathrm{Al}_{2} \mathrm{O}_{3} \text {-water nanofluids } \\
\left.\phi_{p}>1 \%\right) \text {, } \\
\beta=0.0017\left(100 \phi_{p}\right)^{-0.0841}, \\
f(T, \phi)=\left(-6.04 \phi_{p}+0.4705\right) T \\
\text { and it is valid for } 1 \%<\phi_{p}<4 \% \\
\text { and } 300 K<T<325 K \text {. }\end{array}$ \\
\hline $\begin{array}{l}\text { Prasher et } \\
\text { al. }[28]\end{array}$ & $k_{e f f}=\left(1+A_{e c o} \operatorname{Re}^{M_{e c o}} \operatorname{Pr}^{0.333} \phi\right)\left[\frac{k_{p}+2 k_{b f}+2\left(k_{p}-k_{b f}\right) \phi}{k_{p}+2 k_{b f}-\left(k_{p}-k_{b f}\right) \phi}\right] k_{b f}$ & \\
\hline $\begin{array}{l}\text { Bhattachary } \\
\text { a } \text { et al. [33] }\end{array}$ & $k_{e f f}=\left(1+A_{e c o} \operatorname{Re}^{M_{c o}} \operatorname{Pr}^{0.333} \phi\right)\left[\frac{\left.\left[k_{p}(1+2 \alpha)+2 k_{m}\right]+2 \phi\left[k_{p}(1-\alpha)-k_{m}\right]\right]}{\left[k_{p}(1+2 \alpha)+2 k_{m}\right]-\phi\left[k_{p}(1-\alpha)-k_{m}\right]}\right] k_{b f}$ & \\
\hline $\begin{array}{l}\text { Xu et al. } \\
{[34]}\end{array}$ & $\frac{k_{e f f}}{k_{b f}}=\frac{k_{p}+2 k_{b f}-2 \phi\left(k_{b f}-k_{p}\right)}{k_{p}+2 k_{b f}+\phi\left(k_{b f}-k_{p}\right)}+H_{c o} \frac{N u d_{b f}}{\operatorname{Pr}} \frac{\left(2-D_{f}\right) D_{f}}{\left(1-D_{f}\right)^{2}} \frac{\left[\left(\frac{d_{\max }}{d_{\text {min }}}\right)^{1-D_{f}}-1\right]^{2}}{\left[\left(\frac{d_{\text {max }}}{d_{\text {min }}}\right)^{2-D_{f}}-1\right]} \frac{1}{\bar{d}_{p}}$ & \\
\hline $\begin{array}{l}\text { Vladkov } \\
\text { and Barrat } \\
{[35]}\end{array}$ & $\frac{k_{e f f}}{k_{b f}}=\frac{\left(\frac{k_{p}}{k_{b f}}(1+2 \Omega)+2\right)+2 \phi\left(\frac{k_{p}}{k_{b f}}(1-\Omega)-1\right)}{\left(\frac{k_{p}}{k_{b f}}(1+2 \Omega)+2\right)-\phi\left(\frac{k_{p}}{k_{b f}}(1-\Omega)-1\right)}$ & $\begin{array}{l}\Omega=\varsigma k_{b f} / r_{p} \text { is the ratio between } \\
\text { the Kapitza length (equivalent } \\
\text { thermal thickness of the interface) } \\
\text { and the particle radius. }\end{array}$ \\
\hline $\begin{array}{l}\text { Yu-Hua et } \\
\text { al. [38] }\end{array}$ & $\frac{k_{e f f}}{k_{b f}}=\frac{k_{p_{e f f}}+2 k_{b f}-2 \phi_{e f f}\left(k_{b f}-k_{p_{e f f}}\right)}{k_{p_{e f f}}+2 k_{b f}+\phi_{e f f}\left(k_{b f}-k_{p_{e f f}}\right)}+\frac{\rho_{p} \phi_{e f f} c_{p}}{2 k_{b f}} \sqrt{\frac{K_{B} T}{3 \pi r_{c} \mu}}$ & \\
\hline Shukla & & \\
\hline
\end{tabular}




\begin{tabular}{|c|c|c|}
\hline Dhir [39] & $\begin{array}{l}k_{e f f}\left\{\frac{k_{p}+2 k_{b f}+2 \phi\left(k_{p}-k_{b b}\right)}{k_{p}+2 k_{b f}-\phi\left(k_{p}-k_{b f}\right)}\right\}_{b f}+\phi \frac{\rho_{p} c_{p} K_{B} T}{\gamma}+ \\
\left\{\frac{n K_{B}^{2} T}{\gamma}\right\}\left\{\frac{(1-\phi) Z}{8\left(1+\left(\rho_{i} / n Z\right)\right)}\right\}\left\{\frac{3.29\left(r_{p} \kappa_{D}\right)^{2}+3.61\left(r_{p} K_{D}\right)+1.89}{a \kappa_{D}\left(1+r_{p} \kappa_{D}\right)^{2}}\right\}+ \\
\left\{\frac{\rho_{p} c_{p} K_{B} T}{\gamma}\right\}\left\{\frac{(1-\phi) Z}{16\left(1+\left(\rho_{i} / n Z\right)\right)}\right\}\left\{\frac{9.87\left(r_{p} \kappa_{D}\right)^{2}+21.64\left(r_{p} \kappa_{D}\right)+17.05}{r_{p} K_{D}\left(1+r_{p} \kappa_{D}\right)^{2}}\right\}+ \\
\left\{\frac{\rho_{p} c_{p} K_{B} T}{\gamma}\right\}\left\{\frac{(1-\phi)^{2} Z^{2}}{48\left(1+\left(\rho_{i} / n Z\right)\right)^{2}}\right\}\left\{\frac{1.92\left(r_{p} \kappa_{D}\right)^{4}+1.80\left(r_{p} \kappa_{D}\right)^{3}+1.05\left(r_{p} \kappa_{D}\right)^{2}+0.29\left(r_{p} \kappa_{D}\right)}{\left(1+r_{p} \kappa_{D}\right)^{4}}\right\}\end{array}$ & \\
\hline Yang [40] & $k_{d i f f}=\left[1+3 \phi \frac{\frac{r_{p}}{R_{b} k_{b f}}-1}{\frac{r_{p}}{R_{b} k_{b f}}+2}\right] k_{b f}+157.5 \phi_{p} c_{f} u_{p}^{2} \tau$ & \\
\hline $\begin{array}{l}\text { Murshed et } \\
\text { al. [102] }\end{array}$ & $k_{e f f}=\frac{\left(k_{p}-k_{n l}\right) \phi_{p} k_{n l}\left(2 \Pi_{2}^{3}-\Pi_{1}^{3}+1\right)+\left(k_{p}+2 k_{n l}\right) \Pi_{2}^{3}\left\{\phi_{p} \Pi_{1}^{3}\left(k_{n l}-k_{p}\right)+k_{b f}\right\}}{\left(k_{p}+2 k_{n l}\right) \Pi_{2}^{3}-\left(k_{p}-k_{n l}\right) \phi_{p}\left(\Pi_{2}^{3}-\Pi_{1}^{3}+1\right)}$ & $\begin{array}{l}\text { spherical nanoparticles } \\
\Pi_{1}=1+\frac{\delta_{n l}}{r_{p}} \text { and } \Pi_{2}=1+\frac{\delta_{n l}}{2 r_{p}}\end{array}$ \\
\hline $\begin{array}{l}\text { Murshed et } \\
\text { al. [102] }\end{array}$ & $k_{e f f}=\frac{\left(k_{p}-k_{n l}\right) \phi_{p} k_{n l}\left(\Pi_{2}^{2}-\Pi_{1}^{2}+1\right)+\left(k_{p}+2 k_{n l}\right) \Pi_{2}^{2}\left\{\phi_{p} \Pi_{1}^{2}\left(k_{n l}-k_{p}\right)+k_{b f}\right\}}{\left(k_{p}+2 k_{n l}\right) \Pi_{2}^{2}-\left(k_{p}-k_{n l}\right) \phi_{p}\left(\Pi_{2}^{2}-\Pi_{1}^{2}+1\right)}$ & $\begin{array}{l}\text { cylindrical nanoparticles } \\
\Pi_{1}=1+\frac{\delta_{n l}}{r_{p}} \text { and } \Pi_{2}=1+\frac{\delta_{n l}}{2 r_{p}}\end{array}$ \\
\hline $\begin{array}{l}\text { Shima et al. } \\
\text { [103] }\end{array}$ & $\frac{k_{n f}}{k_{b f}}=\left(1+P_{c o} \operatorname{Re}^{p_{s d e}} \operatorname{Pr}^{0.333} \phi\right)\left[\frac{1+2\left(\frac{k_{p}-k_{b f}}{k_{p}+2 k_{b f}}\right) \phi}{1-\left(\frac{k_{p}-k_{b f}}{k_{p}+2 k_{b f}}\right) \phi}\right] k_{b f}$ & \\
\hline $\begin{array}{l}\text { Jung and } \\
\text { Yoo [44] }\end{array}$ & 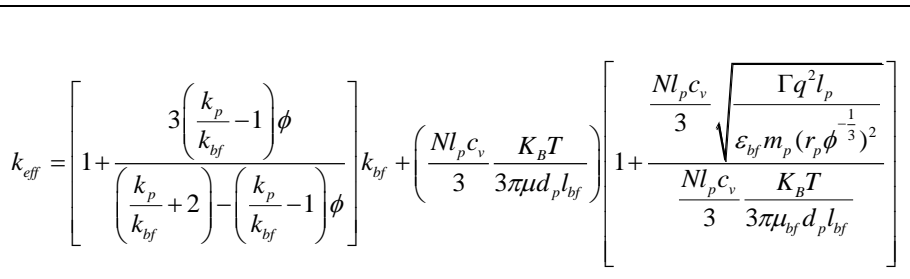 & \\
\hline $\begin{array}{l}\text { Yu and } \\
\text { Choi [54] }\end{array}$ & $k_{e f f}=\frac{k_{p e}+2 k_{b f}+2\left(k_{p e}-k_{b f}\right)\left(1+\frac{\delta_{n l}}{r_{p}}\right)^{3} \phi}{k_{p e}+2 k_{b f}-\left(k_{p e}-k_{b f}\right)\left(1+\frac{\delta_{n l}}{r_{p}}\right)^{3} \phi} k_{b f}$ & \\
\hline
\end{tabular}




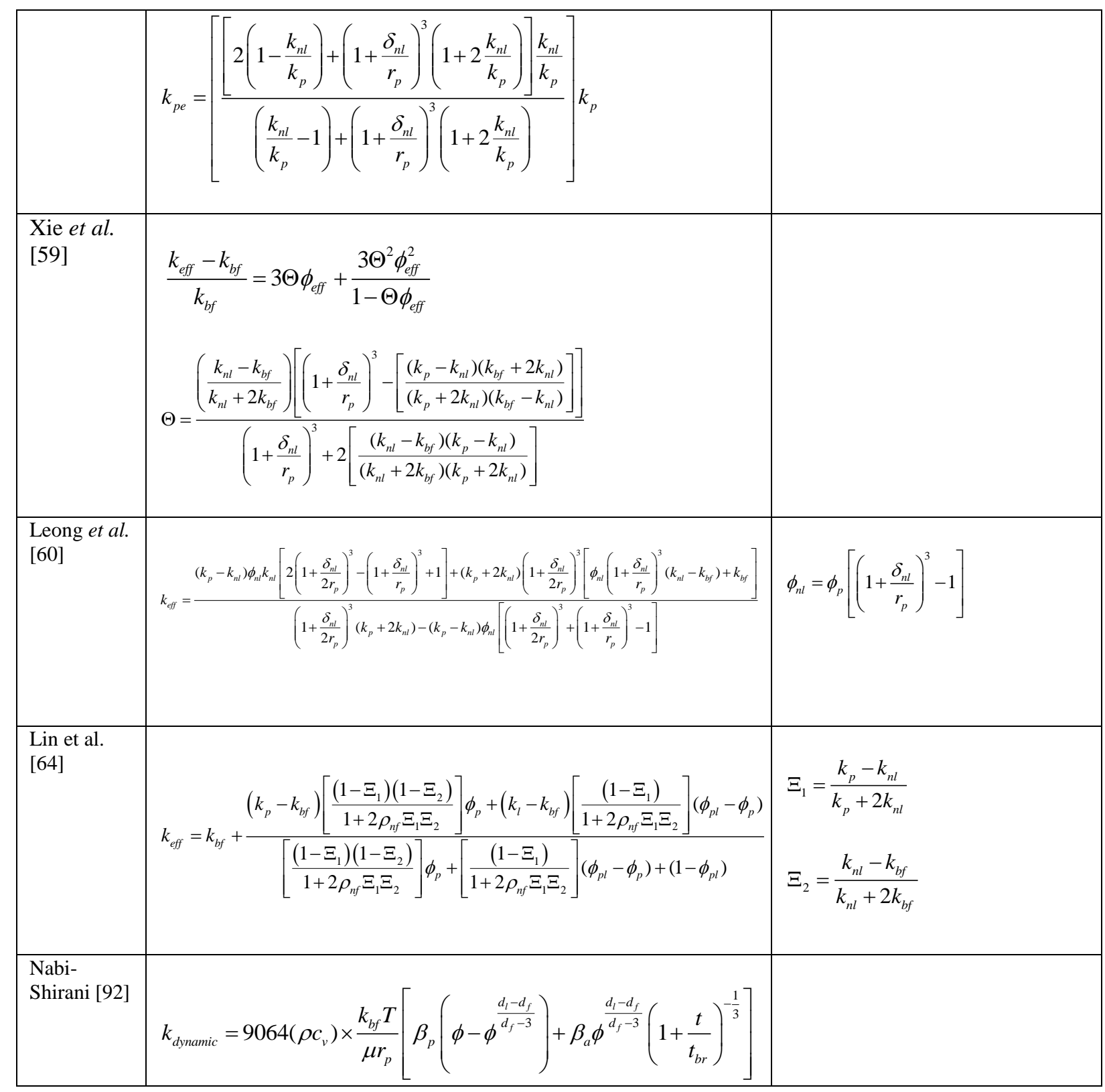




\section{List of Figure Captions}

Fig. 1: Modes of energy transport in a nanofluid (adapted from [19])

Fig. 2: Comparison of models with experimental data for $\mathrm{Al}_{2} \mathrm{O}_{3}$

Fig. 3: Comparison of models with experimental data for $\mathrm{CuO}$ 


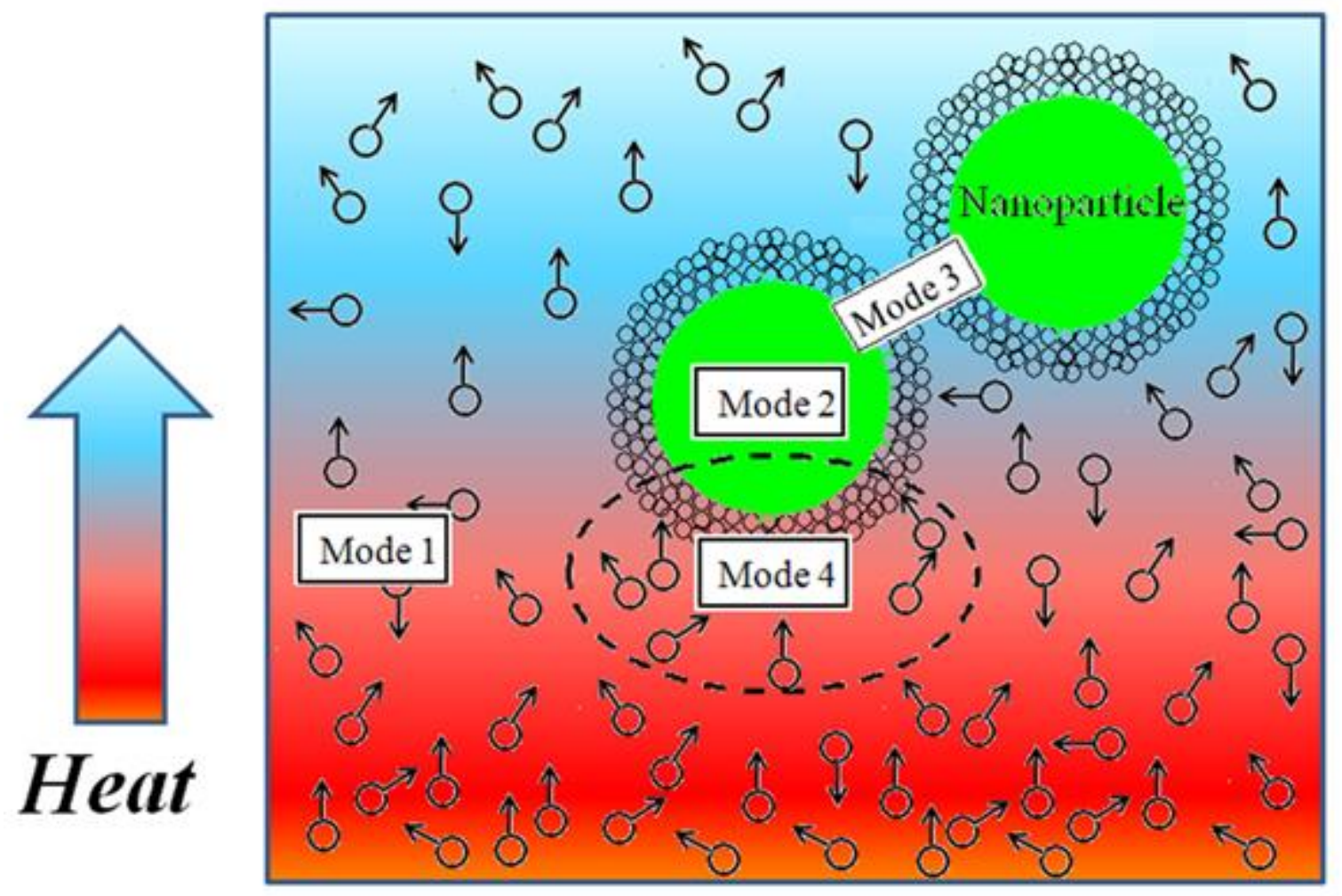

Fig. 1: Modes of energy transport in a nanofluid (adapted from [19]) 


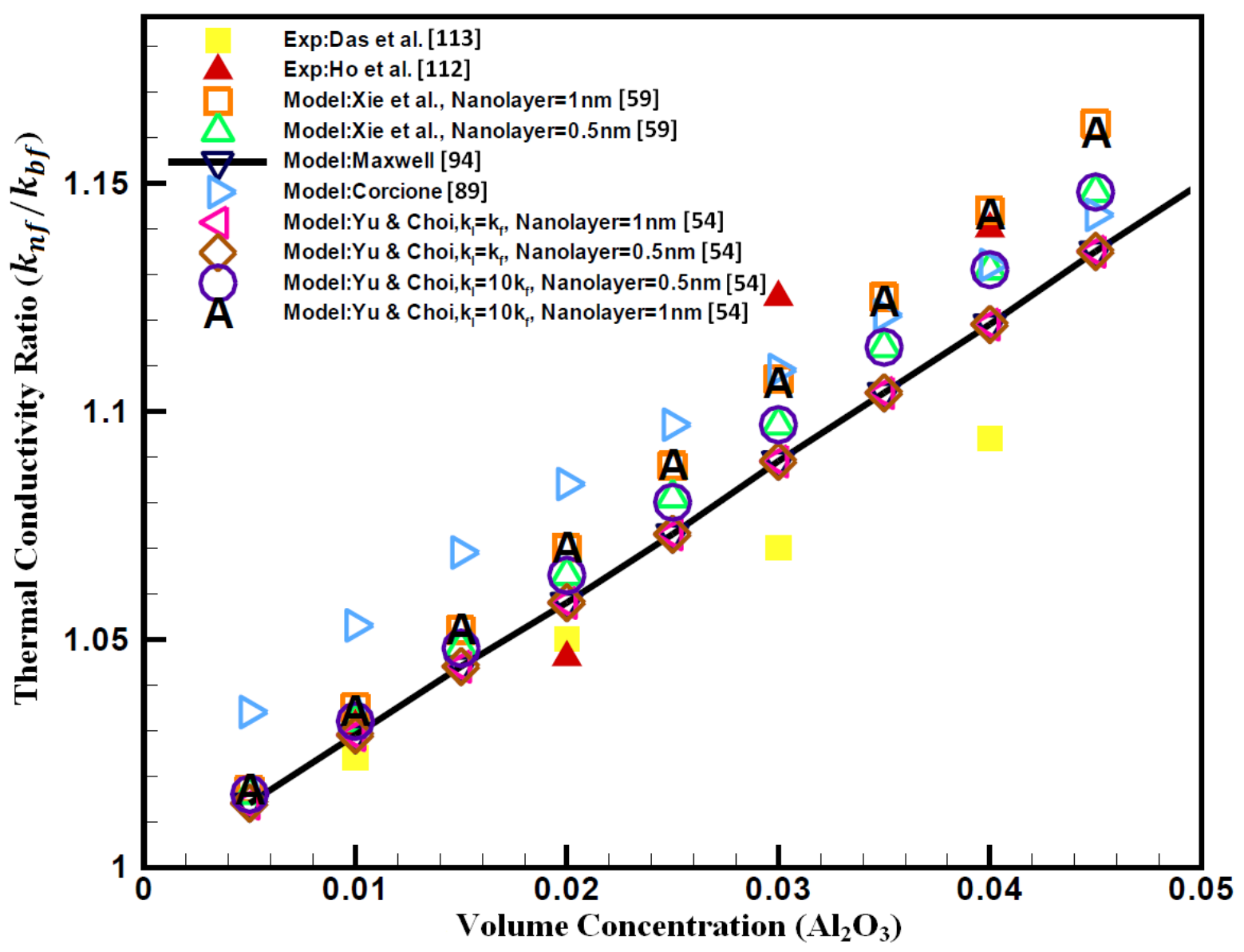

Fig. 2: Comparison of models with experimental data for $\mathrm{Al}_{2} \mathrm{O}_{3}$ 


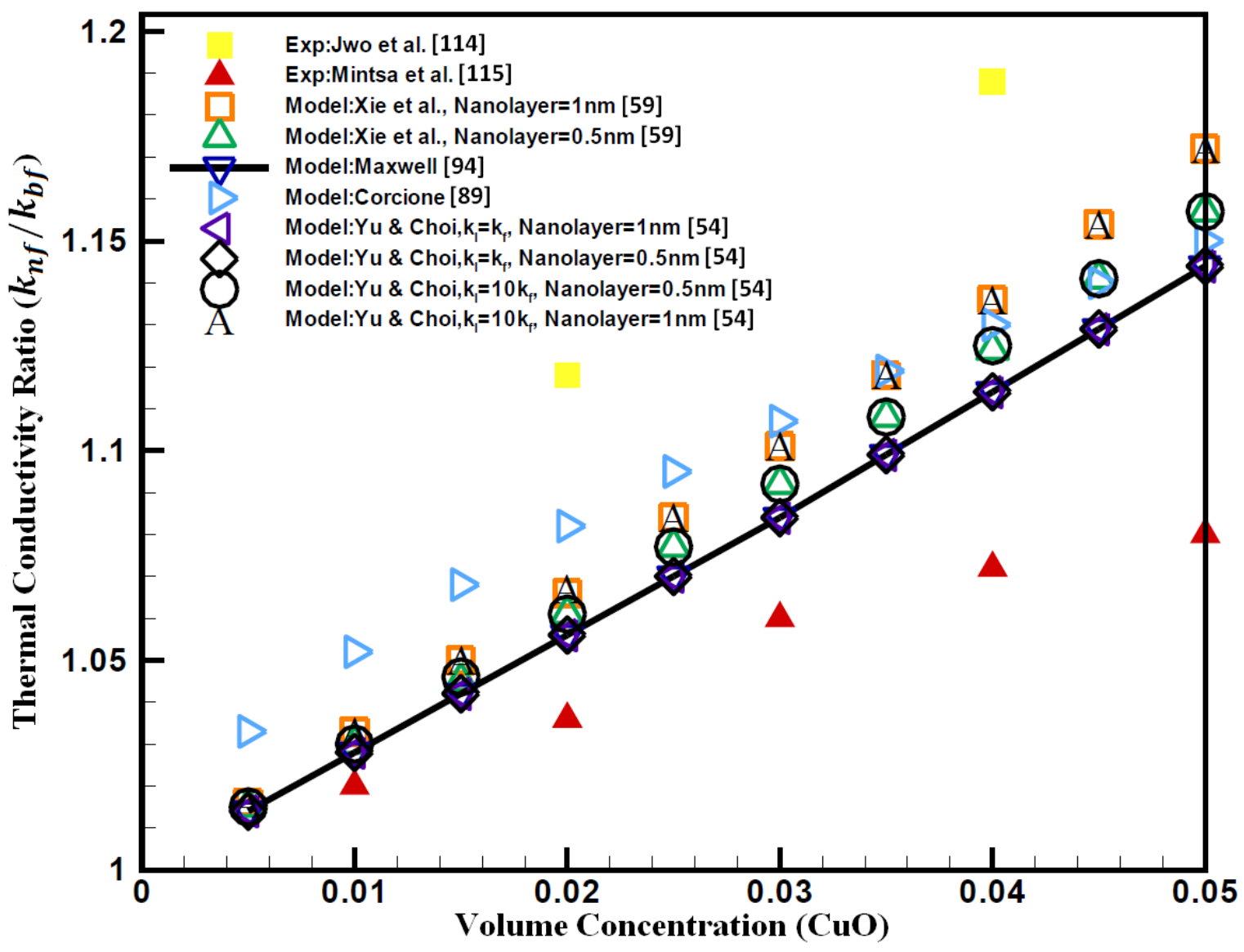

Fig. 3: Comparison of models with experimental data for $\mathrm{CuO}$ 


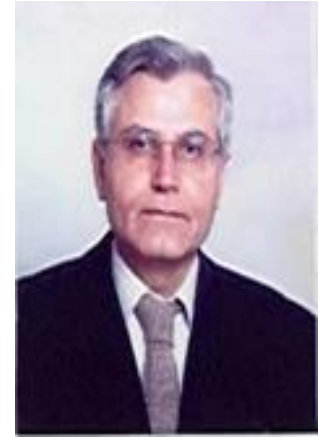

Hikmet Ş. Aybar, after completing his BS study at Istanbul University in 1978 and his MS study at the Technical University of Istanbul in 1982, received a Turkish government scholarship to study for the $\mathrm{PhD}$ degree in the USA. After completing his MS study at Ohio State University in 1987, he worked as a research associate in the Department of Chemistry at Ohio State University for one year. He received his $\mathrm{PhD}$ degree in 1992 from the Department of Mechanical Engineering at Ohio State University, and he started his career as a senior R\&D engineer at the Turkish Atomic Energy Authority in Ankara. In February 1995, he joined the Department of Mechanical Engineering at Eastern Mediterranean University as Assistant Professor, he became Associate Professor in September 1995, and he became Professor in 2004. He has served as Graduate Committee Chairman in the Department of Mechanical Engineering since 2000. He has served as Vice Dean of the Engineering Faculty since 2008. His research interests are computational heat and fluid flow, nuclear and fossil-fuel-fired power generation, thermal systems design, solar heating and solar desalination, magnetic material and applications (e.g. magnetic cooling and magnetic heat engine) and nanofluids.

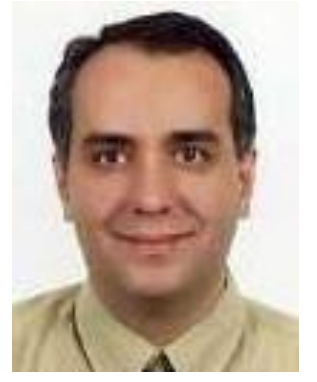

Mohsen Sharifpur is a senior lecturer and also responsible for nanofluid research laboratory in the Department of Mechanical and Aeronautical Engineering at the University of Pretoria. He received his BSc in Mechanical Engineering from Shiraz University, Iran. He completed his MSc in Nuclear Engineering, and then he received a full scholarship for $\mathrm{PhD}$ study in Mechanical Engineering (thermal-fluid) from Eastern Mediterranean University. He was the only one among all the postgraduate students who achieved four out of four for the CGPA when he received his $\mathrm{PhD}$. He is the author and co-author of more than 40 articles and conference papers. His research interests include convective multiphase flow, thermal-fluid behaviour of nanofluids, porous media and waste heat to work in thermal systems. He is also a reviewer for notable accredited journals.

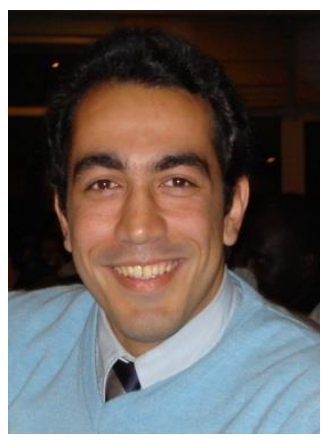

M. Reza Azizian is a PhD candidate at the Priority Research Centre for Energy, department of Chemical Engineering, University of Newcastle in Australia. He received his MSc degree from Eastern Mediterranean University in 2009, working at the Energy Research Centre there as a research assistant since 2007. He received the best honorary degree for his BSc thesis and was ranked in the top $1 \%$ of graduates of Mechanical Engineering at Eastern Mediterranean University. He is also recognised as a Microsoft Systems Administrator (MCP, MCSA). Currently, he is working on thermal properties of magnetite nanofluid. 


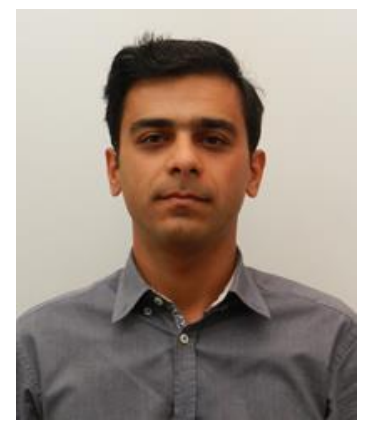

Mehdi Mehrabi is a PhD student at the Thermofluid Research Group, Department of Mechanical and Aeronautical Engineering, University of Pretoria in South Africa. He received his BEng in Mechanical Engineering (Heat and Fluid Flow) in 2006 and his MEng in Mechanical Engineering (Energy Conversion) in 2011, both from Urmia University, Urmia, Iran where he worked on the modeling and optimization of heat transfer processes using artificial intelligent techniques. Currently, he is working on thermal properties of nanofluids. His research interests include convection heat transfer, supercritical fluids, multiobjective optimisation, application of artifitial intelegence techniques for modeling the heat transfer processes, and thermal-fluid behaviour of nanofluids.

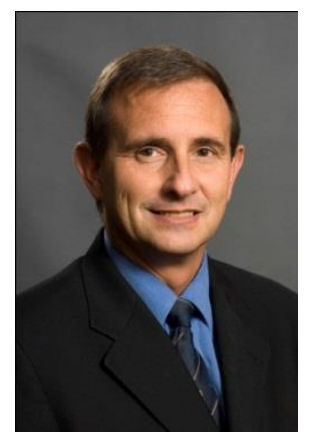

Josua Meyer obtained his BEng (cum laude) in 1984, MEng (cum laude) in 1986, and his $\mathrm{PhD}$ in 1988, all in mechanical engineering from the University of Pretoria and is registered as a professional engineer. After his military service (1988 - 1989), he accepted a position as Associate Professor in the Department of Mechanical Engineering at the Potchefstroom University in 1990. He was Acting Head and Professor in Mechanical Engineering before accepting a position as Professor in the Department of Mechanical and Manufacturing Engineering at the Rand Afrikaans University in 1994. He was Chairman of Mechanical Engineering from 1999 until the end of June 2002, after which he was appointed Professor and Head of the Department of Mechanical and Aeronautical Engineering at the University of Pretoria from 1 July 2002. At present he is the Chair of the School of Engineering. He specialises in heat transfer, fluid mechanics and thermodynamic aspects of heating, ventilation and air-conditioning. He is the author and co-author of more than 450 articles, conference papers and patents and has received various prestigious awards for his research. He is also a fellow or member of various professional institutes and societies such as the South African Institute for Mechanical Engineers, South African Institute for Refrigeration and Air-Conditioning, American Society for Mechanical Engineers, American Society for Air-Conditioning, Refrigeration and AirConditioning, and is regularly invited to be a keynote speaker at local and international conferences. He has also received various teaching and exceptional achiever awards. He is an associate editor of Heat Transfer Engineering and Editor of the Journal of Porous Media. 